NBER WORKING PAPER SERIES

\title{
TECHNOLOGICAL PROGRESS AND HEALTH CONVERGENCE: THE CASE OF PENICILLIN IN POST-WAR ITALY
}

\author{
Marcella Alsan \\ Vincenzo Atella \\ Jay Bhattacharya \\ Valentina Conti \\ Iván Mejía-Guevara \\ Grant Miller \\ Working Paper 25541 \\ http://www.nber.org/papers/w25541
NATIONAL BUREAU OF ECONOMIC RESEARCH
1050 Massachusetts Avenue
Cambridge, MA 02138
February 2019

\begin{abstract}
We would like to thank Giovanni Vecchi for useful discussion and comments during the early stage of this research project. Alsan gratefully acknowledges support from the Eunice Kennedy Shriver National Institute of Child Health and Human Development (NICHD) 5K01-HD084709. Bhattacharya thanks the National Institute on Aging (NIA) for support for this work through the Stanford Center for Demography and Economics of Health and Aging (5P30AG017253). Lena Schoemaker, Afia Khan, Anlu Xing and Morgan Foy provided excellent research assistance. The views expressed herein are those of the authors and do not necessarily reflect the views of the National Bureau of Economic Research.
\end{abstract}

NBER working papers are circulated for discussion and comment purposes. They have not been peer-reviewed or been subject to the review by the NBER Board of Directors that accompanies official NBER publications.

(C) 2019 by Marcella Alsan, Vincenzo Atella, Jay Bhattacharya, Valentina Conti, Iván MejíaGuevara, and Grant Miller. All rights reserved. Short sections of text, not to exceed two paragraphs, may be quoted without explicit permission provided that full credit, including () notice, is given to the source. 
Technological Progress and Health Convergence: The Case of Penicillin in Post-War Italy Marcella Alsan, Vincenzo Atella, Jay Bhattacharya, Valentina Conti, Iván Mejía-Guevara, and Grant Miller

NBER Working Paper No. 25541

February 2019

JEL No. I10,J10,N00

\section{$\underline{\text { ABSTRACT }}$}

Throughout history, technological progress has transformed population health, but the distributional effects of these gains are unclear. New substitutes for older, more expensive health technologies can produce convergence in population health outcomes, but may also be prone to "elite capture" leading to divergence. This paper studies the case of penicillin using detailed mortality statistics and exploiting its sharply-timed introduction in Italy after World War II. We find penicillin reduced both the mean and standard deviation of infectious diseases mortality, leading to substantial convergence across disparate regions of Italy. Our results do not appear to be confounded by competing risks or mortality patterns associated with World War II.

Marcella Alsan

Stanford Medical School

Center for Health Policy/PCOR

117 Encina Commons, Room 218

Stanford, CA 94304

and NBER

malsan@stanford.edu

Vincenzo Atella

University of Rome Tor Vergata

atella@uniroma2.it

Jay Bhattacharya

117 Encina Commons

CHP/PCOR

Stanford University

Stanford, CA 94305-6019

and NBER

jay@stanford.edu
Valentina Conti

Food and Agriculture Organization of

the United Nations

Viale delle Terme di Caracalla

Rome 00153

Italy

valentinaconti23@yahoo.it

Iván Mejía-Guevara

Center for Population Health Sciences

Stanford University

Stanford, CA 94305

imejia@stanford.edu

Grant Miller

CHP/PCOR

Stanford University

117 Encina Commons

Stanford, CA 94305-6019

and NBER

ngmiller@stanford.edu 


\section{Introduction}

Technological progress in medicine has been described as a leading explanation for the increase in post-World War II era (Davis 1956; Preston 1975; Easterlin 1999; Mokyr 2002; Acemoglu and Johnson 2007) and is often put forth as a solution to health challenges in developing countries. Yet technological progress can also have unintended consequences for the distribution of disease. If only elites can afford a health technology, or if a technology is a private good that might substitute for public good provision, such innovation could widen health disparities, at least initially (Mosca 1939; Olson 1965; Kremer and Willis 2016; Ashraf et al. 2016). Alternatively, "breakthrough" health technologies that are less expensive may supplant older, more expensive ones may encourage population health convergence.

In this paper, we analyze the effects of the introduction of penicillin, arguably one of the most important medical technologies of the twentieth century (Tomes 1990, 1998). Discovered to kill Staphylococcus bacteria by Alexander Fleming in 1928 - and successfully isolated and produced by Howard Florey, Ernst Chain, and Norman Heatley in 1939 this new "miracle drug" quickly became the first-line treatment for pneumonia, diphtheria, syphilis, gonorrhea, scarlet fever, and other infectious diseases (Dowling 1977; Levy 1992). ${ }^{1}$ Penicillin's achievements were preceded by those of sulfa agents, the first chemotherapy developed to fight infection and the subject of scholarship by Jayachandran, Lleras-Muney and Smith (2010), who find the introduction of sulfa drugs led to impressive reductions in maternal mortality and pneumonia deaths in the historical United States. ${ }^{2}$

We build off the Jayachandran et al. (2010) study in two ways: first, by exploring the role penicillin had on average mortality in Italy following its introduction by the United

\footnotetext{
${ }^{1}$ The Lancet published a high-profile article in 1943 entitled "General and Local Administration of Penicillin," describing the effectiveness of penicillin in treating wounded soldiers in North Africa (Florey and Florey 1943). Some scholars estimate that penicillin saved at least 300,000 lives during the Second World War (Dowling 1977; Levy 1992; Ratcliff 1945).

${ }^{2}$ Conybeare (1948), Loudon (1988), and Mackenbach and Looman (1998) also provide suggestive evidence on the importance of antibiotics. By contrast, some studies suggest that penicillin did not have the dramatic effect commonly attributed to it (Hemminki and Paakkulainen (1976) studying Finland and Sweden, for example).
} 
Nations in the aftermath of World War II, and second, and more generally, by documenting the effects of the technology on the distribution of mortality. ${ }^{3}$ Some scholars suggest that the distribution of new technologies, even inexpensive ones, often benefit the elite first (Brenzel and Claquin 1994). Others suggest that more portable technologies which do not require large scale infrastructure investments are less prone to elite capture and have considerable potential to improve population health (Acemoglu and Robinson 2008; Mosca 1939; Olson 1965). For penicillin, this could be particularly true given that political decision-making often targeted expensive water and sanitation infrastructure - which can greatly reduce the spread of infectious diseases - towards more elite neighborhoods and communities (Bigatti 2014; Massarutto 2011; Picci 2002; Troesken 2004). Finally, technological progress may be "necessary" but not "sufficient" for health convergence - institutions may be critical to ensure benefits are distributed to those most in need.

To study the distributional consequences of the introduction of penicillin, we assemble a dataset of Italian vital records spanning much of the twentieth century (Atella, Francisci and Vecchi, 2017). We use these data to estimate the contribution of penicillin to infectious disease mortality decline in Italy during the twentieth century. Focusing on the years between 1924 and 1955, we first establish its average effect on mortality by interacting the sharp timing of penicillin introduction with causes of death sensitive to penicillin, controlling for timeand region-level effects as well as regional linear time trends. We then estimate penicillin's effect on the distribution of mortality in four ways: first, by analyzing changes in the age distribution of deaths over time, using Kolmogorov-Smirnov (KS) tests to detect significant differences in these distributions year-by-year; second, using our econometric approach akin to our framework for studying mean reductions in mortality rates, but testing for differential declines by initial level of infectious disease death rates; third, testing for $\beta$-convergence, following the literature on macroeconomic growth and economic convergence (Barro and Sala-i-Martin 1992); and, fourth, testing for $\sigma$-convergence by estimating the relationship

\footnotetext{
${ }^{3}$ Sulfa drugs are distinct from beta-lactam antibiotics, of which penicillin is the first developed (Mandell, Douglas and Bennett 2010).
} 
between penicillin introduction and changes in the standard deviation of regional mortality rates (Janssen et al. 2016).

We find sharply-timed reductions in penicillin-sensitive mortality rates across Italy that closely coincide with the introduction of penicillin in 1947. There are no trend differences between penicillin-sensitive and penicillin-insensitive diseases prior to 1947, and the subsequent decline of about 0.3 deaths per thousand annually represents a $66 \%$ reduction relative to the average rate of penicillin-sensitive deaths in earlier years. Then, using all four estimation approaches, we find clear evidence of mortality rate convergence across regions of Italy. Relative to years prior to 1947, the introduction of penicillin reduced the dispersion of penicillin-sensitive mortality rates across regions by $68 \%$, explaining $40 \%$ of all-cause convergence over this period.

We also consider two important threats to the internal validity of our analyses. The first is competing risks. Because our estimation framework relies on comparisons between penicillin-sensitive and penicillin-insensitive diseases, reductions in penicillin-sensitive deaths could mechanically increase non-communicable disease (NCD) mortality as those benefitting from penicillin live long enough to suffer and die from non-infectious causes. We show that competing risks are not a threat in practice because the decline in penicillin sensitive death rates is present when examining a simple change over time (i.e. not making comparisons with NCDs). Furthermore, even when the sample time frame is limited to a very short window following pencillin's debut, thereby reducing the movement of infectious disease survivors into deaths due to non-infectious causes, we still find statistically significant and medically meaningful effects. The second issue is that penicillin was introduced shortly after the end of World War II. Infectious disease mortality rates commonly surge during wartime (Erdem et al. 2011; Zapor and Moran 2005), so their decline relative to non-infectious mortality rates could partly reflect the end of conflict and regression to the mean. However, our results are similar across areas with varying degrees of war-related destruction and are robust to excluding years 1943-1945 (the years of most intense conflict in Italy) from our estimation. 
The paper proceeds as follows. Section II provides historical background on public health in Italy and the introduction of penicillin, and Section III describes the construction of the dataset. Section IV focuses on the role of penicillin for mean reductions in mortality, and examines penicillin's contributions to population health convergence. Section V presents estimation results. Section VI considers competing risks and presents other robustness checks, and Section VII concludes.

\section{Background}

\section{II.A Early Efforts to Combat Infectious Disease Mortality in Italy}

At the time of unification in 1861, life expectancy at birth in Italy was approximately 29 years, and the crude death rate was about 35 per 1,000 people (Atella, Francisci and Vecchi, 2017). In 1887, Francesco Crispi's government introduced the country's first sanitary reforms under the Crispi-Pagliani law. ${ }^{4}$ However, infectious disease deaths in Italy did not begin to decline until the early twentieth century, which historians link to improvements in municipal hygiene under provisions of the law governing water quality and sanitation in urban areas (Giovannini 1996; Giuntini 1999; Pogliano 1984). During fascist rule (1920-1943), public health initiatives targeted the so-called "triple endemic diseases:" malaria, syphilis, and tuberculosis. ${ }^{5}$

Italy's nascent healthcare system and reforms often failed to reach its poorest members (Giovannini 1996; Giuntini 1999; Pogliano 1984). ${ }^{6}$ Municipal authorities were responsible for providing healthcare to the indigent, yet in practice private charitable organizations

\footnotetext{
${ }^{4}$ The establishment of a health system is interpreted by historians as one of the most important achievements of Italian "political and moral life" at the beginning of the new Kingdom [Croce (1928), cited in Cosmacini (2005), p. 345].

${ }^{5}$ The most important provisions focused on malaria were issued between 1923 and 1934 through a series of laws designed to arrive at a thorough land reclamation operation (bonifica integrale). The Consolidation Act on the reclamation of marshlands was approved with Royal Decree no. 3256 of 30 December 1923. Law no. 3134 of 24 December 1928, called the "Mussolini Law," granted financial resources to land reclamation and provided for integration regarding the supply of drinking water and the construction of rural buildings, hamlets, and roads.

${ }^{6}$ The law's principles of universalism became effective only in 1978, when the Italian National Health Service System (SSN) was established.
} 
provided these services (Opere Pie, or "Pious Organizations"). ${ }^{7}$ A Royal Decree in 1884 established that private firms could invest in the water sector (Ermano and Massarutto 2012). Massarutto (2011) argues this decree and the ensuing privatization directed water supply towards the wealthy in urban areas. As late as the 1950 s, only $52 \%$ of private houses in Italy received potable water (Doria 2010), and only $7 \%$ had all three utilities: potable water, adequate sanitation, and electricity (Barra Bagnasco 1996). ${ }^{8}$

Mortality rates in Italy declined on average during the early- to mid-1900s (see Figure 1), though wide regional health disparities in infectious disease mortality were prevalent at the beginning of this period (Figure 2, Panel A). Nationally, life expectancy at birth in Italy rose to 40-45 years - but varied by as much as 12 years across regions. ${ }^{9}$ These regional disparities peaked in 1925-1930, remained high until WWII, and then declined sharply at the end of the war. Understanding whether the introduction of penicillin contributed to the compression of regional mortality rates is a central focus of this paper.

\section{II.B The Advent of Penicillin in Italy}

The supply of penicillin in Italy began in 1947 (Luzzi 2004). In its early stage of distribution (1945 and 1946) penicillin was available in Italy through international aid only, imported by the UNRRA (United Nations Relief and Rehabilitation Administration) channel and limited in quantity. At that time the black market was flourishing. Therefore, having enough money and connections, people could reach for the drug (the initial distribution of penicillin in Italy by the US Army started with the main intent of using it to treat the spreading of venereal

\footnotetext{
${ }^{7}$ The "non-poor" generally used services provided by individual private-practice doctors (medici liberoesercenti) who made home visits.

${ }^{8}$ Until the end of WWII, national public spending for infrastructure was concentrated in the North. On public investments in water, a Royal Decree issued in 1884 created a dualism in the management of water services: water was public, but private companies could invest in the sector once awarded government licenses (Ermano 2012). As a result, water was largely provided to wealthy families in urban areas (Massarutto 2011). Although many subsequent laws governing water management were issued between 1861 and 1950, universalism in the water sector was not achieved until the late 1950s (Mantelli and Temporelli 2007). Modern water infrastructure in poorer southern regions was completed only in the late 1980s (Mantelli and Temporelli, 2007).

${ }^{9}$ During the 1920s the regional variation in life expectancy at birth was almost as large as that estimated for Indian states between 2011 and 2016 - ranging from 61.5 years in Madhya Pradesh to 77 years in Kerala (Ponnapalli et al., 2013).
} 
diseases). To resolve this problem ENDIMEA (Ente Nazionale Distribuzione Medicinali agli Alleati) was established, which began its work on October 1st, 1944. Since January 1st, 1945, each provincial health office began to communicate to the General Directorate of Public Health (DGSP), within the Ministry of the Interior, estimates of the demand for medicines for the quarter. The DGSP, based on the requests and the availability of drugs, granted the drugs to the applicants, informing ENDIMEA to ship the product to the local private wholesalers. Once the wholesaler collected the drugs, he was responsible for the distribution of medicines to the Provincial Health Offices. The latter also had an obligation to follow the drug during the journey from the wholesaler warehouse to the pharmacies or hospitals, in order to prevent theft and illegal sales. ${ }^{10}$

Italian patients could receive the new drug free of charge if requested by their physicians. Provincial Health Offices were held accountable for any shortages of medicines, and pharmacists received a high margin for the sale of antibiotics, which discouraged the emergence of an underground market favoring the wealthy (Battini 1946; Luzzi 2004).

\section{Data}

\section{III.A Vital Statistics Data ${ }^{11}$}

The Italian National Statistical Office (ISTAT) provides national vital statistics in annual Health Statistics Yearbooks (Annuario di Statistiche Sanitarie) starting from 1887. Vital statistics for years 1924-1955 were digitized at the region-year-cause of death level. ${ }^{12}$

Harmonizing Regions. ISTAT data provides death counts for Italy's regions over time.

\footnotetext{
10 The Italian health authorities were responsible for any shortages of medicines. In the spring of 1945 the drug became available via physician prescription, but only in the City Public Health Offices (Ufficio d'Igiene). In 1947, the pharmaceutical company "SPA Milan" became the first private Italian company to market antibiotics, selling Supercillin (in vials) and Prontocillin (tablets). A year later, the Anglo-American monopoly over penicillin was broken by Domenico Marotta, then-director of the Istituto Superiore di Sanit, who called Ernst Chain to lead the International Centre for Microbiological Chemistry in Rome.

${ }^{11}$ For a complete description of the vital statistics, see Appendix A.

${ }^{12}$ To the best of our knowledge, formal demographic analyses of the quality and completeness of Italy's historical mortality statistics have not been published. However, Italian vital statistics back to the nineteenth century are included in the Human Mortality Database (HMD), and data quality is a central criterion for HMD inclusion. http://www.mortality.org/. (Data documentation for Italy HMD available at: http: //www . mortality.org/hmd/ITA/InputDB/ITAcom.pdf).
} 
Due to changes in administrative regional borders over our period of investigation, we had to aggregate some regions. From 1924 until the end of WWII, Italy was organized into 18 administrative regions with only minor changes across region borders. The only exception was the establishment of Valle dAosta in September 1945. For this reason, to obtain a harmonized regional dataset from 1924 to 1954 we treat Piedmont and Valle dAosta as a single region. Thus, our sample includes the following 18 regions: Piedmont and Valle d'Aosta, Lombardy, Trentino Alto Adige, Veneto, Friuli Venezia Giulia, Liguria, Emilia Romagna, Tuscany, Umbria, Marche, Lazio, Abruzzi and Molise, Campania, Apulia, Basilicata, Calabria, Sicily and Sardinia. ${ }^{13}$

Harmonizing Cause of Death. Officially, ISTAT assumed the responsibility of collecting mortality data at individual level only in 1930, following Law no. 2238 issued in December 1929. Previously, the statistical office was within the Ministry of Agriculture, Industry and Trade via Indagine sulle cause di morte. ISTAT collects this information using an official reporting format ("Scheda di morte") following international standards recommended by the World Health Organization (WHO). These individual death certificates consist of two parts. A general practitioner or coroner certifies the first part and ascribes cause. The "initial cause" - disease or trauma - is recorded, which may have led to additional complications but initiated a causal chain leading to death. Diagnostic codes are then assigned to each death using WHO International Classification of Diseases (ICD) criteria. The second part is completed by a municipal civil registrar and includes information about the demographic and social characteristics of the deceased.

Causes of death reported in Italy's vital records change over time. We therefore use categories that can be consistently identified and tracked across all study years, effectively adopting the classification used in 1956-1957 for all years of our analysis (1924-1955). ${ }^{14} \mathrm{We}$

\footnotetext{
${ }^{13}$ For sake of completeness, in December 1963 the region of Molise was established by splitting the "Abruzzi and Molise" into two distinct regions. This last change brought Italy to have the current administrative structure based on 20 regions.

${ }^{14}$ The 17 causes of death are the following: infective and parasitic diseases; tumors; allergic and endocrine glands diseases; blood and hematopoietic diseases; psychic and personality disorders; nervous system diseases; circulatory system diseases; respiratory system diseases; digestive system diseases; genitourinary system dis-
} 
then classify each of these causes that can be consistently tracked over time according to whether or not it can be treated with penicillin. Ultimately, this process yields 79 penicillininsensitive, 15 penicillin-sensitive, and 15 unclassified diseases. ${ }^{15}$ In our analysis of causespecific mortality we exclude unclassified deaths.

Constructing war related destruction indicator. We measure destruction related to World War II using the number of military and civilian deaths directly related to war causes at the regional level that occurred between 1940 and 1945 (ISTAT 1957). ${ }^{16}$

Constructing Rates. Finally, using death counts by region, year, and cause, we construct mortality rates using data on regional populations in Italy over time. Specifically, to create population denominators, we use regional population counts from Italy's decennial population censuses provided by ISTAT. For inter-censual years, population estimates accounting for births and deaths provides estimates of this population construction process using several sources of population data (Vecchi, 2017; see Appendix A for more details). ${ }^{17}$

eases; complications of pregnancy; skin and tissue diseases; bones and locomotive organs diseases; congenital malformations; early childhood particular diseases; senility and pathologic states; accidents, traumatisms, and poisonings. The coding system adopted during years 1924-1955 has changed from the International Analytical Classification (IAC) to the ISTAT Intermediate Classification (IIC) adopted in subsequent years. Moreover, from 1958 onwards, there is a higher disaggregation of diseases with respect to years 1956-1957, due to the inclusion of new death-related causes.

${ }^{15}$ The list of "penicillin-sensitive" and "penicillin-insensitive" categories of death are reported in Appendix B.

${ }^{16}$ The war victims are quantified according to the region of actual death, delivering a space/time quantification of war conflicts. WWII severity indicator in Italy is provided by the official publication "Morti e dispersi per cause belliche negli anni 1940-45" (The dead and the missing due to war causes between 1940-1945) (ISTAT, 1957). The intensity of war destruction was quantified based at the median. Regions above-median conflict deaths are: Piedmont-Valle d'Aosta, Veneto, Friuli Venezia Giulia, Emilia Romagna, Toscana, Umbria, Marche, Lazio. Lombardy, Trentino Alto Adige, Abruzzi and Molise, Campania, Puglia, Basilicata, Campania, Sicilia, Sardegna. See Atella, Di Porto, and Kopinska (2017) for a detailed description of the data used. WWII-related death rates were then computed by dividing death county by the average regional population between 1940-1945.

${ }^{17}$ Population estimates were interpolated into age bins of $0-25,26-30,31-35,36-40,41-45,46-50,51-$ $55,56-60,61-65,66-70,71-75$, and $76+$ by using known population data for years 1921-1927, 1931-1936, 1943-1950, 1953, 1957, and 1959-1961. To estimate missing population data, we broke the age bins into separate individual age columns and assumed a uniform population distribution for each age within an age bin. We interpolated missing age-specific population by taking the current year's age-specific population and adding the previous year's age-specific mortality to get the previous year's age-specific population. We use the same methodology in the opposite direction by interpolating the age-specific population data of the subsequent year by taking the current year's age-specific population and subtracting the current year's population age-specific mortality. Afterwards, we re-aggregated the age columns into the original age bins for the population controls of our study. 
Our final sample contains region-year-cause of death observations for years 1924-1959.

Table 1 shows descriptive statistics on all-cause mortality for penicillin-sensitive and penicillininsensitive diseases before and after penicillin introduction.

\section{III.B Human Mortality Database (HMD) Data}

We also use national-level data on age-specific deaths from the Human Mortality Database (HMD) in two ways (HMD 2017). ${ }^{18}$ First, because the regional vital statistics do not contain information about deaths by age, precluding age-adjustment, we control for age-specific population counts. ${ }^{19}$ Second, we directly examine changes in the age distribution of deaths over time as an alternative strategy for studying mortality convergence.

\section{III.C Graphical Analysis}

Mortality Decline by Cause. As Figure 1 shows, Italy's total mortality rate fell substantially between 1924 and 1955. However, this decline varied dramatically by cause - and in particular, by penicillin sensitivity. Panel A of Figure 2 shows that with the official introduction of penicillin in 1947, the decline in regional mortality rates for penicillin-sensitive causes accelerated sharply. Moreover, the variance in regional death rates sensitive to penicillin became markedly more compressed beginning in 1947, with substantial convergence occurring by the mid-1950s. Panel B of Figure 2 demonstrates regional mortality rates for non-infectious causes did not decline over the entire period - nor did their variance. ${ }^{20}$

\footnotetext{
${ }^{18}$ National-level HMD estimates are constructed by HMD investigators using vital statistics, population censuses, and population estimates directly from ISTAT and from other researchers working on behalf of ISTAT. Death counts in the Italian vital statistics are based on the de facto population ("popolazione presente") until 1980 and on the de jure population ("popolazione residente") afterwards. Therefore, mortality rates before 1981 in the HMD are based on population estimates of the de facto population, calculated from census counts to consider this change in the coverage of vital statistics (Glei 2015). Death counts from the vital statistics are also adjusted both to include missing military deaths during World Wars I and II and to spatially redistribute deaths by age and calendar year (Jdanov et al. 2008). For the period 1937-51, intercensal survival methods are used to derive population estimates using pre- and post-war census counts (Jdanov et al. 2008).

${ }^{19}$ This data is also available online at:http://www.mortality.org/

${ }^{20}$ More work is required to address concerns about the confounding role of World War II given that infectious disease deaths often exceed direct casualties due to conflict (Erdem et al. 2011; Zapor and Moran 2005). We address this issue later in Section VI.B. Further, one might also argue that WWII has favored internal migration flows from poorer to richer regions, thus contributing to higher differentials among regional mortality rates. Atella, Deb and Kopinska (2019) show that the phenomenon of migration within Italian
} 
Mortality Decline by Age. Figure 3 depicts the age distribution of period life table deaths in Italy for years between 1924 and 1955. The figure reveals substantial reductions in infant and child mortality over time (which are generally due to infectious causes, mostly penicillinsensitive (Vercelli et al. 2014)). As a result, deaths appear to become more concentrated at older ages - a pattern consistent with convergence, although the timing of this compression is less readily evident (Section VI investigates this issue more closely).

Standard Deviation and Average Life Expectancy: Figure 4 shows both life expectancy at birth and the standard deviation of age at death across regions (a common indicator used in the literature to measure mortality convergence and lifespan inequality (Edwards and Tuljapurkar 2005; Gillespie et al. 2014)) by year. Life expectancy at birth increases from 51.5 in 1924 to 57.6 in 1939, declines abruptly during WWII until the 1943 Italian armistice, recovers quickly to its pre-war level, and continues to increase in the post-war years. The standard deviation of age at death declines little during the pre-war period (as life expectancy at birth is rising), remains relatively constant during WWII, and then declines precipitously beginning in the late 1940s (around the time that penicillin was introduced) and throughout the post-war period. This rapid decline beginning in the latter 1940s is suggestive of mortality convergence.

Standard Deviation by Cause: Figure 5 shows the standard deviation of regional death rates separately for the all-cause mortality rates, penicillin-sensitive mortality rates, and penicillin-insensitive mortality rates over time. Before WWII, the standard deviation trajectories of penicillin-sensitive and -insensitive mortality rates were similar. Both experience disruptions during the war period, but after 1947 the standard deviation of penicillin-sensitive mortality rates across regions converges, while the standard deviation of penicillin-insensitive mortality rate slightly diverges.

regions began in earnest in 1951. 


\section{Estimation}

\section{IV.A Mortality Decline}

Building on graphical evidence shown in Figures 2 and 4, our empirical strategy tests for sharply-timed differential trend breaks in penicillin-sensitive mortality rates (relative to penicillin-insensitive mortality rates) coincident with the introduction of penicillin in 1947. Specifically, we estimate:

$$
m_{i c t}=\alpha+\gamma_{i}+\delta_{t}+\theta_{c}+\beta\left(I_{t}^{\text {post }} * \text { Sensitive }_{c}\right)+X_{i t} \varphi+\gamma_{i} * t+\epsilon_{i c t},
$$

for regions $i$, causes of death $c$, and years $t . m_{i c t}$ is a region-cause-year specific death rate (specified both in level and natural $\log$ form). $I_{t}^{\text {post }}$ is a dummy variable equal to one for observations in years 1947 or later, Sensitive is a dummy variable for whether or not cause $c$ is sensitive to penicillin, and $X$ is a vector of covariates including interpolated population estimates in discrete age categories. We include year, region, and disease fixed effects, and our preferred specification also includes linear time trends interacted with region dummies. Standard errors are clustered by region, and we report p-values corresponding to block bootstrapped standard errors. ${ }^{21}$

We also assess the temporal dynamics of the introduction of penicillin by substituting a vector of year dummy variables for , $I_{t}^{\text {post }}$ in Equation (1):

$$
m_{i c t}=\alpha+\gamma_{i}+\delta_{t}+\theta_{c}+\sum_{j} \rho_{j}\left(\text { Sensitive }_{c} * I_{t}^{j}\right)+X_{i t} \varphi+\gamma_{i} * t+\epsilon_{i c t},
$$

where $I_{t}^{j}$ is a vector of $j$ year dummy variables and all other variables are defined as before.

\footnotetext{
${ }^{21}$ To assess the robustness of our results, we also estimate variants of specification (1), using both levels and $\log$ specifications and including region-specific linear time trends.
} 


\section{IV.B Mortality Convergence}

To study mortality convergence at the national level, we first analyze changes in the distribution of age at death (Kannisto 2000; Fries 1980; Wilmoth and Horiuchi 1999). Specifically, we use Kolmogorov-Smirnov (K-S) tests to formally assess if the timing of statistically significant changes in the distribution of age at death coincides with the introduction of penicillin in 1947, comparing the distribution in each year between 1924-1954 with the last year in our sample, $1955 .^{22}$

Second, we test for mortality convergence associated with the introduction of penicillin using an econometric framework similar to the one that we use for estimating mean reductions in penicillin-sensitive mortality rates. Specifically, we re-estimate Equation (1), stratifying by the pre-1947 level of both penicillin-sensitive mortality rates and overall regional mortality rates.

Third, we test for $\beta$-convergence, or convergence in levels of mortality rates, following the approach of Barro and Sala-i-Martin (1992) to study convergence in Gross Domestic Product (GDP) per capita across countries. This approach assesses if regions with higher pre-1947 penicillin-sensitive and -insensitive mortality rates converged towards regions with lower mortality rates by sub-periods (before and after the introduction of penicillin, 19291946 and 1947-1955). Specifically, we estimate:

$$
\frac{\left(m_{i c t}-m_{i c t_{0}}\right)}{\left(t-t_{0}\right)}=\alpha+\gamma_{i}+\beta m_{i c t_{0}}+\epsilon_{i t}
$$

where $m_{i c t}$ is the mortality rate in region $i$ due to cause $c$ in initial year $t_{0}\left(t_{0}=1924\right.$ for the first sub-period, and $t_{0}=1947$ for the second sub-period) and $\beta$ is the parameter of interest.

Finally, we test for $\sigma$-convergence, or convergence in the standard deviation of mortality

\footnotetext{
${ }^{22} \mathrm{~A}$ two-sample Kolmogorov-Smirnov statistic is used to test whether two empirical one-dimensional distribution functions $\left(F_{m}(x), G_{n}(x)\right)$ differ from each other. The KS statistic is defined by the formula $D_{m n}=\sup _{x}\left|F_{m}(x)-G_{n}(x)\right|$. The null hypothesis that the two samples come from the same distribution is rejected, at the level of significance $\alpha$, when $D_{m n}>c(\alpha) \sqrt{\frac{m+n}{m n}}$, where $c(\alpha)=\sqrt{-\frac{1}{2} \ln \left(\frac{\alpha}{2}\right)}$ (Stephens, 1974).
} 
rates, across regions of Italy by re-estimating Equation (1) using the standard deviation of cause-specific mortality rates by region as the dependent variable (Janssen et al. 2016; Young et al. 2008).

\section{Results}

\section{V.A Mortality Decline}

Table 2 reports results obtained by estimating Equation (1). Conditioning on year, region, and disease fixed effects as well as the regional age distribution, mortality rates among diseases sensitive to penicillin relative to those insensitive fell by approximately 0.3 per thousand (and is statistically distinguishable from zero, $\mathrm{p}<0.01$ ) with the introduction of penicillin. Relative to the mean mortality rate among deaths due to these causes prior to 1947 (0.469, see Table 1$)$, this represents a reduction of 58\%. ${ }^{23}$ Column 2 adds regionspecific linear time trends. In both cases, the estimate of $\beta$ is robust, with the mortality rate decline associated with the introduction of penicillin remaining at about 0.3 per 1,000. Columns 3 and 4 repeat this estimation for log mortality, showing robust reductions in penicillin-sensitive mortality rates.

Figure 6 then examines the dynamic pattern of mortality decline associated with penicillin introduction in Italy, showing estimates and $95 \%$ confidence intervals for each year-specific $\rho_{j}$ in Equation (2). Prior to the introduction of penicillin, there is little evidence of preexisting declines in penicillin sensitive mortality rates (relative to insensitive ones). Yearspecific estimates drop with the introduction of penicillin in 1947 and become negative and statistically different from zero by 1948 (and in all subsequent years) with the diffusion of penicillin. By the end of our study period in 1955, these year-specific estimates approach a decline of 2.8 per 1,000 deaths.

\footnotetext{
${ }^{23}$ To estimate this effect we divide the post-1947 mean average reduction in the cause-specific mortality (regression coefficient in the first column of Table 2: -0.272), by the mean mortality rate for penicillin-sensitive causes in the baseline period, between 1924-1946.
} 


\section{V.B Mortality Convergence}

Figure 7 first shows year-by-year K-S p-values for tests of differences between each year's distribution of age at death against the distribution in 1955 (the last year in our sample). These p-values remain constant at nearly 0 for all years prior to the introduction of antibiotics, indicating strongly significant differences from 1955 - and then beginning in 1947, these p-values rapidly rise to 1 (indicating no difference from 1955). This sharply-timed compression in Italy's age distribution of deaths is highly consistent with the introduction of antibiotics leading to convergence in mortality rates.

Table 3 reports estimates obtained from Equation (1), stratified by level of penicillinsensitive mortality rates prior to 1947 (above and below the median). The first and second columns show that after 1947, penicillin-sensitive mortality rates declined more in regions with higher (above median) initial rates (by 0.29 per 1,000 ) than in those with lower (below median) initial rates $(0.26$ per 1,000$)$ - and significantly so. Compared to the mean of the pre-1947 penicillin-sensitive cause-specific mortality, these changes represent reductions of $61 \%$ and $55 \%$, respectively.

Table 4 reports $\beta$-convergence estimates from Equation (3). Comparing penicillinsensitive mortality rates before vs. after the introduction of penicillin, the estimate of $\beta$ is almost four times greater after penicillin introduction (-0.075 vs. -0.021). Alternatively, for penicillin-insensitive mortality rates, the estimate is not statistically significant prior to 1947 - and is positive and statistically different from 0 afterwards, suggesting divergence in penicillin-insensitive mortality rates.

Finally, Table 5 (columns (1) and (2)) present estimates of sigma convergence by using the standard deviation of deaths across regions and years for each of the two disease categories as the dependent variable. We find that the standard deviation of penicillin-sensitive mortality declines after penicillin is introduced $(-0.113, \mathrm{p}<0.01)$ - but not the standard deviation

of penicillin-insensitive mortality $(-0.004)$. The results remain consistent after truncating the sample in 1950 (row 2): the standard deviation of penicillin-sensitive mortality declines 
significantly $(-0.089, \mathrm{p}<0.01)$, but not for penicillin-insensitive mortality $(-0.009) .{ }^{24}$

\section{Identification and Threats to Validity}

In this section, we discuss two potential treats to our interpretation of the effects of the introduction of antibiotics on infectious disease mortality. In Section VI.A, we consider the problem of competing risks - specifically, the survival benefit of antibiotics increased the exposure of the population to death from non-infectious causes. In Section VI.B, we discuss how the chaotic end to World War II may have affected infectious disease mortality in Italy during our sample period.

\section{VI.A Competing Risks}

In our context, the competing risks problem concerns a possible increase in non-communicable disease (NCD) mortality resulting from fewer people dying from infectious disease mortality as a result of the introduction of penicillin. This phenomenon can influence our estimates given that we compare penicillin-sensitive vs. penicillin-insensitive death rates over time (Tsiatis, 1975; Peterson, 1976; Honorè and Lleras-Muney 2006). In this section we study the influence that competing risks has on our estimation of the contribution of penicillin to the mortality decline in Italy. ${ }^{25}$ We present a simple framework for defining the particular competing risk problem inherent in our main estimating equation, and describe an alternative approach to bound the estimates.

Period 0: In any period, deaths can be divided into mortality from two etiologies $E=$ $\{I, N C\}$ where $I$ indicates infectious diseases and $N C$ reflects non-communicable diseases.

$$
D=I+N C
$$

\footnotetext{
${ }^{24}$ We use a truncated sample to test the potential treat of competing risks in the interpretation of the effects of the introduction of penicillin on infectious disease mortality, including our interpretation of sigma convergence - see Section VI.A.

${ }^{25}$ Technically, if competing risks is a problem, it amounts to a violation of the Stable Unit Treatment Value Assumption (SUTVA), which is necessary for unbiased estimates in a difference-in-difference framework such as ours.
} 
note that deaths from etiology $E$ can be expressed as the mortality rate from $E$ multiplied by the number of susceptible from that etiology at time $t: E=\mu^{e, t} * S^{E, t}$. We assume that mortality rate from non-communicable disease is exogenous to penicillin and, after period 0 , there are $N^{0}$ persons surviving in this closed population without births or migration.

Period 1: At the beginning of period 1, penicillin, $p$, is introduced which immediately treats and cures those afflicted with infectious diseases, leading to a direct decline in mortality associated with diseases of infectious etiology:

$$
D^{1}=S^{I, 1} \mu^{I, 1}(p)+S^{N C, 1} \mu^{N C}
$$

Period 2: By period 2, there are now indirect effects of penicillin, since those weaker individuals that otherwise would have died from infectious disease are now alive (e.g. the harvesting effect of infections has been reduced). These spared lives increase the size of the susceptible non-communicable disease population:

$$
S^{N C, 2}=N^{0}-S^{I, 1} \mu^{I, 1}(p)-S^{N C, 1} \mu^{N C} .
$$

Recall that $\frac{\partial \mu^{I, i}}{\partial p}<0$ by the pharmacology of penicillin and $\frac{\partial S^{N C, 2}}{\partial p}>0$ by equation 6 . Hence the total effect of penicillin over time reflects both the direct effect on infectious deaths and its indirect effect on non-communicable susceptibles.

Our difference-in-differences estimate compares the changes in infectious and non-communicable diseases related deaths, before vs. after the introduction of penicillin: ${ }^{26}$

$$
\left(S^{I, 2} \mu^{I, 2}(p)-S^{I, 0} \mu^{I, 0}\right)-\left(S^{N C, 2}(p) \mu^{N C}-S^{N C, 0} \mu^{N C}\right)
$$

Given that the first term is negative (by the direct effects of penicillin) and the second, in

\footnotetext{
${ }^{26}$ Equation 7 is normalized by total population in our empirical framework. Note there is also a positive effect on susceptibles for infectious diseases at the beginning of period 2, but we ignore that detail since it is dwarfed by the first order effect of penicillin which is to reduce the mortality associated with many communicable causes.
} 
the absence of an overall secular decline in mortality, is positive (by the indirect effects of penicillin), our estimates are biased away from the null. ${ }^{27}$ Yet in our setting, there may be a very prominent secular decline in mortality for all causes - which is why a differencein-differences framework is preferred. Thus, estimates from both the simple and double differences are biased, the former by a secular decline and mis-attribution of penicillin to secular patterns, and the latter by competing risks.

To gauge the relative importance of these two sources of bias, we zoom in on the period very soon after penicillin was introduced (i.e. Period 1), so that our difference-indifferences estimator is not influenced by competing risks (i.e. there is no indirect effects on non-communicable disease): $\left(S^{I, 1} \mu^{I, 1}(p)-S^{I, 0} \mu^{I, 0}\right)-\left(S^{N C, 1} \mu^{N C}-S^{N C, 0} \mu^{N C}\right)$. Shortly after penicillin is introduced, we are more likely to isolate the direct effect of penicillin on the infectious disease mortality as the harvesting and death for more chronic, non-communicable entities would not have not had time to occur. Specifically, we estimate the effect of penicillin on sensitive (i.e. infectious) and insensitive (i.e. non-communicable) causes in a pre vs. post framework and using the full vs. a truncated time period.

These results are gathered in Table 5. For the truncated sample, ending in the year 1950 - three years following the introduction of penicillin into Italy - the results demonstrate that both sensitive and insensitive mortality decline (row (2) columns (3) and (4)) though the effect is much larger for the former. The estimates point to an important secular decline in mortality, independent of penicillin, hence the negative post coefficient in column (4). The difference-in-differences estimate $((-0.486)-(-.0363))$ is about -0.12 , smaller than the main estimates in Table 2 and a lower bound on penicillin's effects.

Using the full sample, with an end year of 1955, the effect of penicillin introduction on insensitive causes is more positive, reflecting the competing risk issue. Yet the magnitude of this change is slight and statistically indistinguishable from the estimates using the 1950 cutoff. Moreover, the fact that the difference-in-differences point estimates are increasing

\footnotetext{
${ }^{27}$ In the presence of a secular decline, the second term will be less negative than in the counterfactual of absent an indirect effect of penicillin.
} 
over time as per our event study is attributable to the first term in equation 7: the direct effect of penicillin on infectious disease mortality (see row (3)). As discussed above, this likely reflects the technology's diffusion. When turning to sigma convergence, there is no major concern for competing risks in any specification: convergence is limited to infectious causes.

In summary, the framework and results presented in this subsection show that the competing risks problem in our context is small, given that a longer time window does not greatly bias the second term in equation 7 in a positive direction. On the other hand, controlling for a secular decline in mortality - which is what differencing out of non-communicable causes affords - is important for obtaining less biased estimates.

\section{VI.B The End of World War II}

Another potential concern with our results is the influence of the end of World War II on infectious disease rates. Because infectious disease mortality rates commonly surge during wartime (Erdem et al. 2011; Zapor and Moran 2005), their decline relative to non-infectious mortality rates could partly reflect the end of conflict. Figure 2 (Panel A) provides at least some prima facie evidence that this is not an important concern in our case - mortality rates sensitive to penicillin are declining until 1930, generally remain stable through 1945 (rather than rising), and then resume their decline. However, we probe this issue further in two ways.

First, we test for differential penicillin effects in areas with varying degrees of war-related destruction. Specifically, we re-estimate Equation (1) separately for regions with aboveand below-median degrees of war intensity, measured using conflict-related mortality rates between 1940 and $1945 .^{28}$ Columns 3 and 4 of Table 3 report estimates separately for regions with higher and lower intensity of exposure to WWII. In general, the penicillin effect is larger in areas with lower war intensity $(0.29$ per 1,000$)$ relative to those with higher war intensity

\footnotetext{
${ }^{28}$ This data is available in "Morti e dispersi per cause belliche negli anni 1940-45" (ISTAT, 1957) and is also online at https:lipari.istat.it/digibib/causedimorte/IST3413mortiedispersipercausebellicheanni1940_45+OCRottimizz.pdf.
} 
(0.26 per 1,000), and this difference is statistically significant. ${ }^{29}$

Second, we simply exclude years 1943-1945 (the years of greatest conflict in Italy) from our sample and again re-estimate Equation (1). Columns 5 and 6 of Table 3 show these results - the estimates are statistically equivalent to those that include these years.

\section{Conclusion}

Although technological progress in health has produced dramatic gains in life expectancy around the globe over the past century, it can also have unintended consequences for the distribution of disease. Health technologies that are inexpensive and substitute for older, more expensive ones may lead to population health convergence, but they could also disproportionately benefit elites, widening health disparities. Notably, there has been little empirical evidence to date on the consequences of major new health technologies for the distribution of health in populations.

Studying the seminal case of penicillin and focusing on Italy using newly digitized vital statistics over several decades, we find that the introduction of penicillin not only reduced average infectious disease mortality rates dramatically (by 58\%), but it also led to a substantial reduction in the variance of mortality rates across Italian regions. Specifically, the standard deviation in the age of death fell by nearly eight years after the introduction of penicillin - a decline of $27 \%$. Our findings relate to the scholarship of researchers investigating postWorld War II health convergence across countries, such as Acemoglu and Johnson (2007) and Deaton (2006), we find that the distribution of penicillin, at least in Italy, played an important role in such convergence and suggest an important role for point-of-care technologies in reducing health inequalities.

\footnotetext{
${ }^{29}$ We test for the significance of the difference between the coefficients obtained in the separate models by pooling the samples used in both models, and specifying a triple interaction that includes an indicator for high and low destruction. The coefficient for this interactions term was statistically significant ( $\mathrm{p}$-values $<$ $0.01)$.
} 


\section{References}

[1] Acemoglu, Daron, and Simon Johnson. 2007. "Disease and Development: The Effect of Life Expectancy on Growth." Journal of Political Economy 115: 925-985.

[2] Acemoglu, Daron, and James A. Robinson. 2008. "Persistence of Power, Elites, and Institutions." American Economic Review 98 (1): 267-93.

[3] Ashraf, Nava, Edward L. Glaeser, and Giacomo A. M. Ponzetto. 2016. "Infrastructure, Incentives, and Institutions." American Economic Review 106 (5): 77-82.

[4] Atella, Vincenzo, Partha Deb, and Joanna A. Kopinska. 2019. "Heterogeneity in longterm health outcomes of Migrants within Italy." Journal of Health Economics 63: 19-33.

[5] Atella, Vincenzo, Edoardo Di Porto, and Joanna Kopinska. 2017. "Stress, Famine and the Fetal Programming: The Long Term Effect of WWII in Italy." CEIS Research Paper 385 .

[6] Atella, Vincenzo, Silvia Francisci, and Giovanni Vecchi. 2017. "Health." In Measuring Wellbeing: A History of Italian Living Standards, edited by Giovanni Vecchi, Oxford University Press.

[7] Barra Bagnasco, M. 1996. "Housing and Workshop Construction in the City." In The Western Greeks, 353-60, edited by G. Pugliese Carratelli. Milan.

[8] Battini, B. 1946. "Servizio di distribuzione della penicillina, in ACISP, Notiziario dell'Amministrazione Sanitaria 1944-1945." Fascicolo unico, Roma, 226-32.

[9] Barro, Robert J., and Xavier Sala-i-Martin. 1992. "Convergence." The Journal of Political Economy 100 (2): 223-51.

[10] Bigatti, Giorgio. 2014. "Da bere per tutti. Servizi idrici e politiche dell'acqua in Italia tra Otto e Novecento. Uno sguardo di sintesi." TST $n^{\circ}$ 26: 110-27.

[11] Brenzel, Logan, and Pierre Claquin. 1994. "Immunization Programs and Their Costs." Social Science $\&$ Medicine 39 (4): 527-36. doi:10.1016/0277-9536(94)90095-7.

[12] Conybeare, John. 1948. "The Effects on Mortality of Recent Advances in Treatment." Journal of the Institute of Actuaries 74: 57-81.

[13] Cosmacini, Giorgio, 2005. "Storia della medicina e della sanità in Italia." Roma: Laterza.

[14] Croce, Benedetto. 1928. "Storia d'Italia dal 1871 al 1915." Bari: Laterza.

[15] Davis, Kingsley. 1956. "The Amazing Decline of Mortality in Underdeveloped Areas." American Economic Review 46 (2): 305-18.

[16] Deaton, A. 2006. The Great Escape: A Review Essay on Fogel's The Escape from Hunger and Premature Death 1700-2100. Journal of Economic Literature 44 (1): 106114. 
[17] Doria, Miguel de França. 2010. "Factors Influencing Public Perception of Drinking Water Quality." Water policy 12 (1): 1-19.

[18] Dowling, Harry. 1977. Fighting Infection: Conquests of the Twentieth Century. Cambridge: Harvard University Press.

[19] Easterlin, Richard. 1999. "How Beneficent Is the Market? A Look at the Modern History of Mortality." European Review of Economic History 3 (3): 257-94.

[20] Edwards, Ryan D., and Shripad Tuljapurkar. 2005. "Inequality in Life Spans and a New Perspective on Mortality Convergence across Industrialized Countries." Population and Development Review 31 (4): 645-674.

[21] Erdem, Hakan, Ahmet Tetik, Ozgur Arun, Bulent Ahmet Besirbellioglu, Omer Coskun, and Can Polat Eyigun. 2011. "War and Infection in the Pre-Antibiotic Era: The Third Ottoman Army in 1915." Scandinavian Journal of Infectious Diseases 43 (9): 690-95. doi:10.3109/00365548.2011.577801.

[22] Ermano, Paolo. 2012. "Gli investimenti nel servizio idrico in Italia: un'analisi storica." DIES Working Paper 3/2012.

[23] Ermano, Paolo, and Antonio Massarutto. 2012. "L'acqua come bene economico: profili allocativi e distributivi." Diritto Pubblico Comparato ed Europeo, 1-2012.

[24] Florey, M. E., and Howard W. Florey. 1943. "General and Local Administration of Penicillin." Lancet 1 (387).

[25] Fries, James F. 1980. "Aging, Natural Death, and the Compression of Morbidity." New England Journal of Medicine 303 (3): 130-5. doi:10.1056/NEJM198007173030304.

[26] Gillespie, Duncan O. S., Meredith V. Trotter, and Shripad D. Tuljapurkar. 2014. "Divergence in Age Patterns of Mortality Change Drives International Divergence in Lifespan Inequality." Demography 51 (3): 1003-17. doi 10.1007/s13524-014-0287-8.

[27] Giovannini, Carla. 1996. "Risanare la citta'. L'utopia igienista di fine Ottocento." Angeli ed., Milano.

[28] Giuntini, Andrea. 1999. "Gli ingegneri sanitari e l'utopia igienista." In Giuntini, A., Minesso, M., Gli ingegneri in Italia tra 800 e 900, Milano, Franco Angeli, 117-128.

[29] Glei, Dana. 2015. "About Mortality Data for Italy." Retrieved from http://www . mortality.org/hmd/ITA/InputDB/ITAcom.pdf (February 14, 2017)

[30] Golini A., Ciucci L., Caselli G. and Istat - Reparto studi sulla popolazione, 1983. Ricostruzione della popolazione residente per sesso, et e regione. Anni 1952-1972". Universit degli Studi di Roma "La Spienza", Dipartimento di Scienze Demografiche, Fonti e strumenti, n.1. 
[31] Hemminki, Elina, and Anneli Paakkulainen. 1976. "The Effect of Antibiotics on Mortality from Infectious Diseases in Sweden and Finland." Am J Public Health. 66 (12): $1180-4$.

[32] Honoré, Bo E., and Adriana Lleras-Muney. 2006. "Bounds in Competing Risks Models and the War on Cancer." Econometrica 74 (6): 1675-98.

[33] Human Mortality Database (HMD). University of California, Berkeley (USA), and Max Planck Institute for Demographic Research (Germany). Available at www.mortality.org or www.humanmortality.de (data downloaded on Jan 28th, 2017).

$\begin{array}{lllll}\text { [34] ICD } & \text { (International } & \text { Classification }\end{array}$ http://www.wolfbane.com/icd/icd6h.htm

[35] ISTAT (National Institute of Statistics) 1956, Annuario di Statistiche Sanitarie (Volume II 1956).

[36] ISTAT (National Institute of Statistics) 1957a, Annuario di Statistiche Sanitarie (Volume III, 1957).

[37] ISTAT (National Institute of Statistics) 1957b. "Morti e dispersi per cause belliche negli anni 1940-45." Rome.

[38] ISTAT (National Institute of Statistics) 1958, Cause di morte 1888-1955, 1958, Roma.

[39] Janssen, Fanny, Anthe van den Hande, Joop de Beer, and Leo J. G. van Wissen. 2016. "Sigma and Beta Convergence in Regional Mortality." Demographic Research 35: 81116.

[40] Jayachandran, Seema, Adriana Lleras-Muney, and Kimberly V. Smith. 2010. "Modern Medicine and the Twentieth Century Decline in Mortality: Evidence on the Impact of Sulfa Drugs." American Economic Journal: Applied Economics 2 (2): 118-46.

[41] Jdanov, Dmitri A., Dana A. Glei, and Domantas Jasilionis. 2008. "A Modeling Approach for Estimating Total Mortality for Italy during the First and Second World Wars." Center for the Economics and Demography of Aging (CEDA) Papers: Paper 20080001CL.

[42] Kannisto, Väinö. 2000. "Measuring the Compression of Mortality." Demographic Research 3. doi:10.4054/DemRes.2000.3.6.

[43] Kremer, Michael, and Jack Willis. 2016. "Guns, Latrines, and Land Reform: Private Expectations and Public Policy." NBER Working Paper 21915.

[44] Levy, Stuart B. 1992. The Antibiotic Paradox: How Miracle Drugs Are Destroying the Miracle. New York: Plenum Press.

[45] Loudon, Irvine. 1988. "Maternal Mortality: 1800-1950. Some Regional and International Comparisons." Social History of Medicine 1: 183-228. 
[46] Luzzi Saverio. 2004. "Salute e sanità nell'Italia Repubblicana." Donzelli Editore, Roma.

[47] Mackenbach, Johan P., and Caspar W. Looman. 1988. "Secular Trends of Infectious Disease Mortality in the Netherlands, 1911-1978: Quantitative Estimates of Changes Coinciding with the Introduction of Antibiotics." International Journal of Epidemiology 17 (3): 618-624.

[48] Mandell Gerald, John Douglas and Raphael Bennett, 2010 Principles and Practices of Infectious Disease Routledge Press : Philadelphia, PA.

[49] Mantelli, Francesco, and Giorgio Temporelli. 2007. "L'acqua nella storia." Milano, Franco Angeli.

[50] Massarutto, Antonio. 2011. "Privati dell'acqua." Bologna, Il Mulino.

[51] Mokyr, Joel. 2002. "Innovation in an Historical Perspective: Tales of Technology and Evolution." In Technological Innovation and Economic Performance, edited by Benn Steil, David G. Victor, and Richard R. Nelson, 23-46. Princeton: Princeton University Press.

[52] Mosca, Gaetano. 1939. The Ruling Class. New York: McGraw-Hill.

[53] Olson, Mancur C. 1965. The Logic of Collective Action; Public Goods and the Theory of Groups. Cambridge: Harvard University Press.

[54] Picci, Lucio. 2002. "Le opere pubbliche dall'unitá d'Italia: l'informazione statistica." Rivista di Politica Economica.

[55] Pogliano, Claudio. 1984. "Scienza e stirpe: eugenica in Italia 1912-1939." Passato e Presente 5, Rivista di storia contemporanea: 61-97.

[56] Ponnapalli, Ramani, Krishna M. Ponnapalli, and A. Subbiah. 2013. "Aging and the Demographic Transition in India and Its States: A Comparative Perspective." International Journal of Asian Social Science 3 (1): 171-193.

[57] Peterson, A. V. 1976. "Bounds for a joint distribution function with fixed subdistribution functions: Application to competing risks." Proceedings of the National Academy of Sciences 73(1), 11-13.

[58] Preston, Samuel H. 1975. "The Changing Relation between Mortality and Level of Economic Development." Population Studies 29 (2): 231-248.

[59] Ratcliff, J.D. 1945. "Yellow Magic: The Story of Penicillin. Random House".

[60] Stephens, M. A. 1974. "EDF Statistics for Goodness of Fit and Some Comparisons." Journal of the American Statistical Association 69 (347): 730-737. doi:10.2307/2286009.

[61] Tsiatis, A. 1975. "A nonidentifiability aspect of the problem of competing risks." Proceedings of the National Academy of Sciences, 72(1), 20-22. 
[62] Tomes, Nancy. 1990. "The Private Side of Public Health: Sanitary Science, Domestic Hygiene, and the Germ Theory, 1870-1900." Bulletin of the History of Medicine LXIV: 509-539.

[63] Tomes, Nancy. 1998. The Gospel of Germs: Men, Women, and the Microbe in American Life. Cambridge: Harvard University Press.

[64] Troesken, Werner. 2004. Water, Race, and Disease. Cambridge: MIT Press.

[65] Vecchi Giovanni. 2017. Measuring Wellbeing. A History of Italian Living Standards. Oxford: Oxford University Press.

[66] Vercelli, Marina, Roberto Lillini, Alberto Quaglia, Rosanna T. Micale, Sebastiano La Maestra, and Silvio De Flora. 2014. "Age-Related Mortality Trends in Italy from 1901 to 2008." PLoS ONE 9 (12). doi:10.1371/journal.pone.0114027.

[67] Wilmoth, John R., and Shiro Horiuchi. 1999. "Rectangularization Revisited: Variability of Age at Death within Human Populations." Demography 36 (4): 475-495. https: //doi.org/10.2307/2648085.

[68] Young, Andrew T., Matthew J. Higgins, and Daniel Levy. 2008. Sigma Convergence versus Beta Convergence: Evidence from U.S. County-Level Data. Journal of Money, Credit and Banking 40 (5): 1083-1093.

[69] Zapor, Michael J., and Kimberly A. Moran. 2005. "Infectious Diseases during Wartime." Current Opinion in Internal Medicine 4 (6): 543-47. 


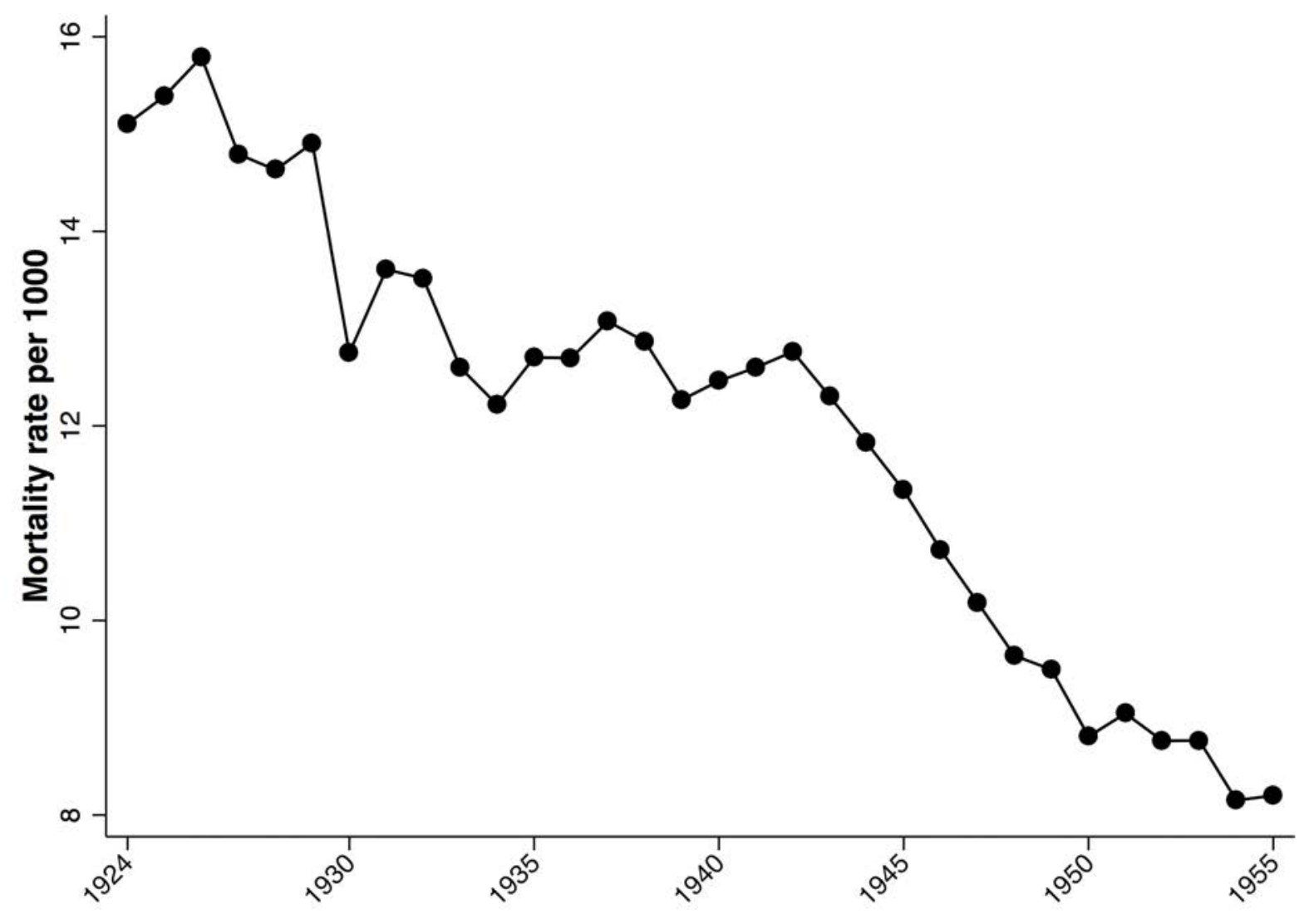

Figure 1: All-cause mortality rates across all regions in Italy, 1924-1955. The unit is number of deaths per 1,000 people. Source: ISTAT 

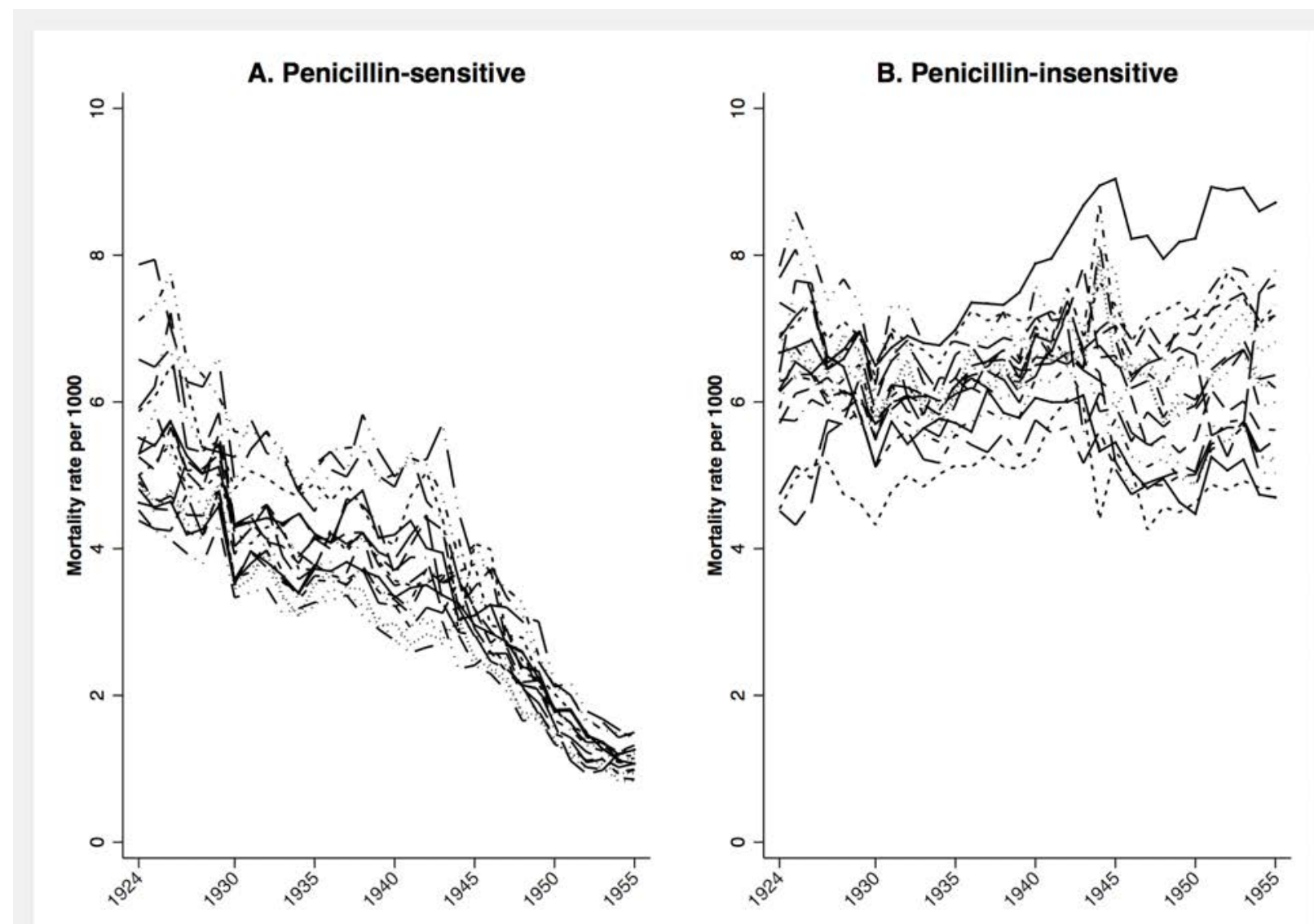

Figure 2: Penicillin-sensitive (Panel A) and penicillin-insensitive (Panel B) disease mortality rates by region in Italy, 1924-1955. The unit is number of deaths per 1,000 people. Source: ISTAT 


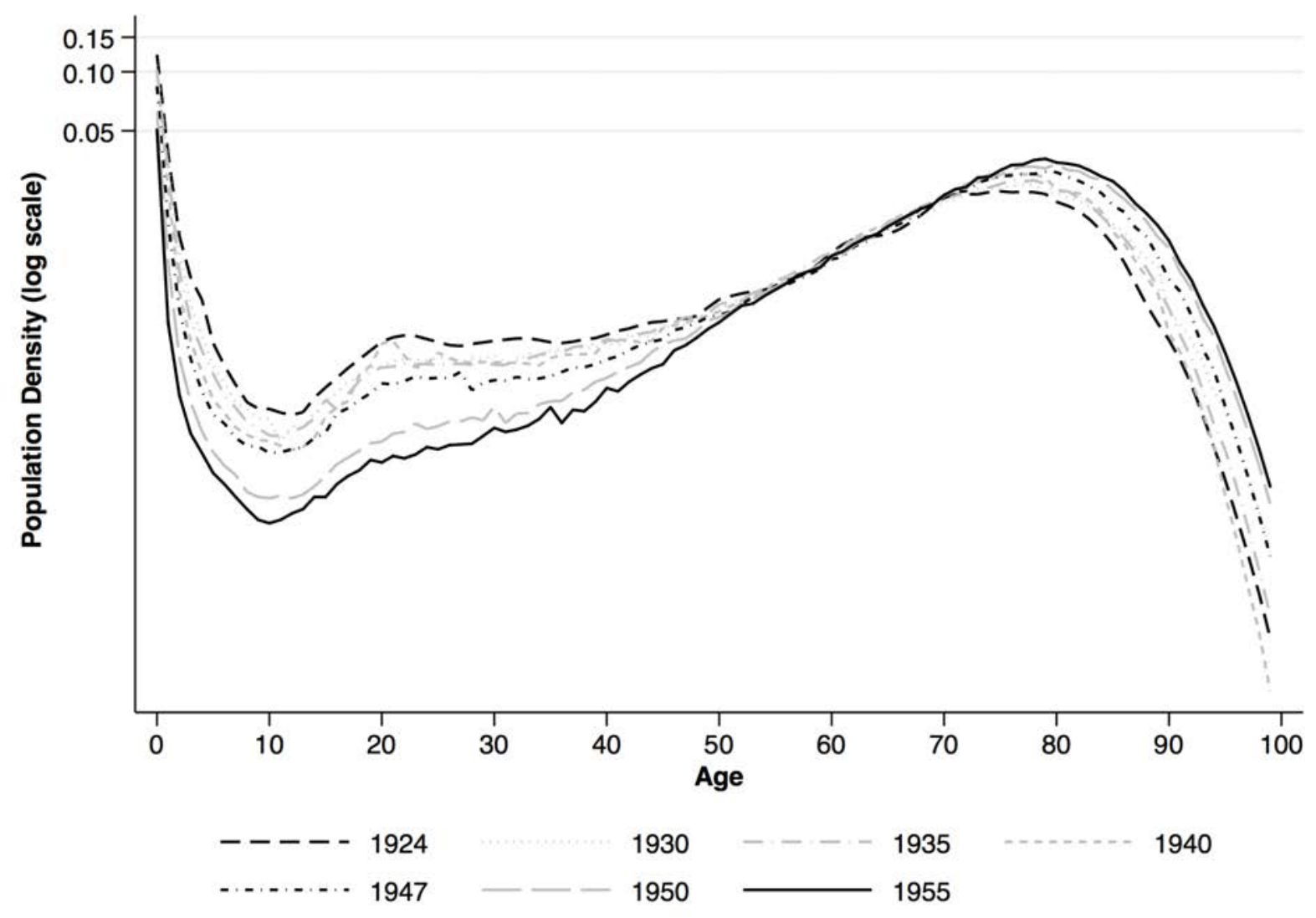

Figure 3: Period life-table distributions of age at death in Italy for selected years between 1924 and 1955. The unit is the logarithm of the probability density of deaths. Source: Human Mortality Database (HMD) 


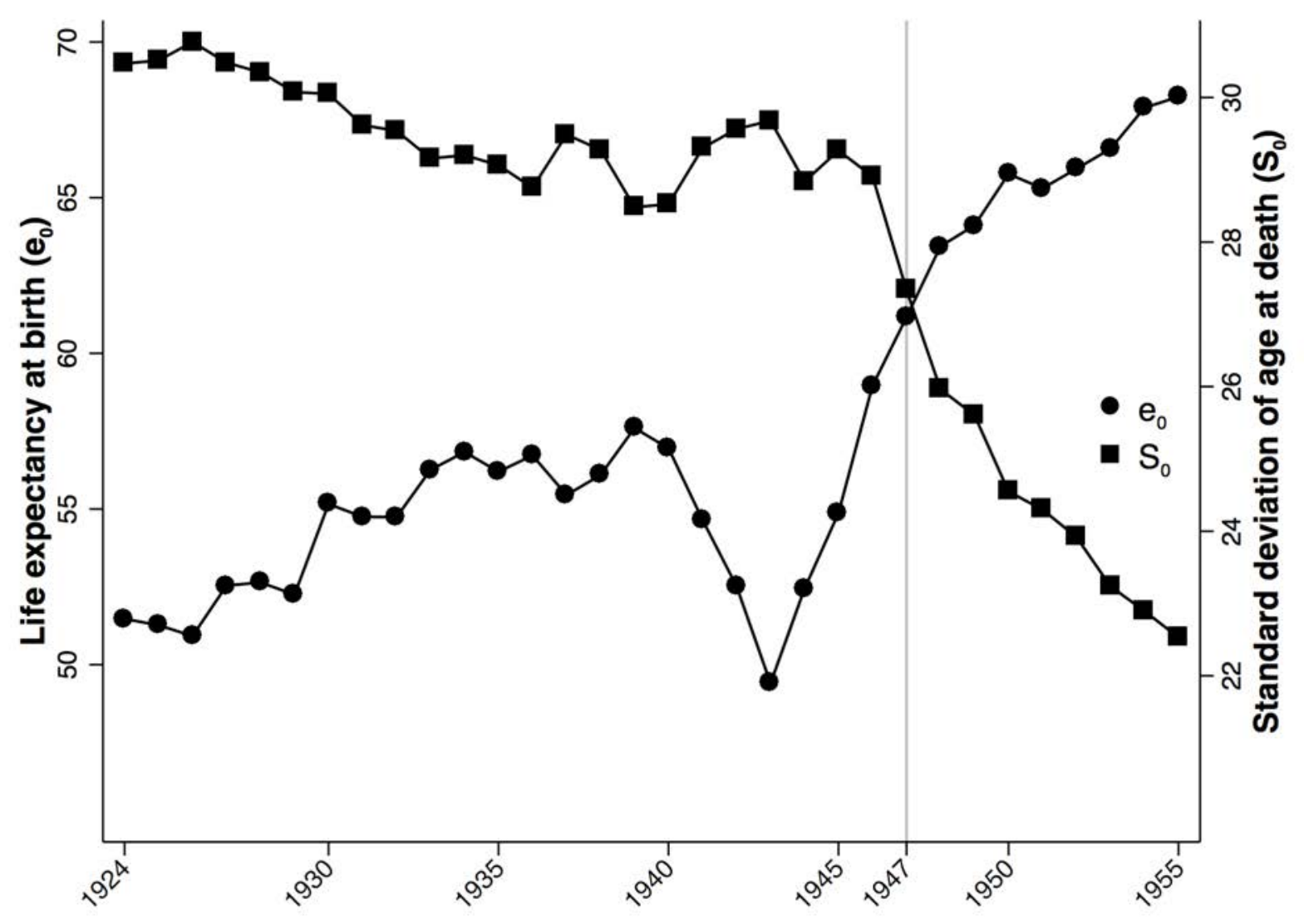

Figure 4: Life expectancy at birth and standard deviation of age at death in Italy, 19241955. The trajectories of the life expectancy at birth (left-hand side scale), and the standard deviation of age at death (right-hand side scale)are based on the distributions of age at death from Fig. 3. 


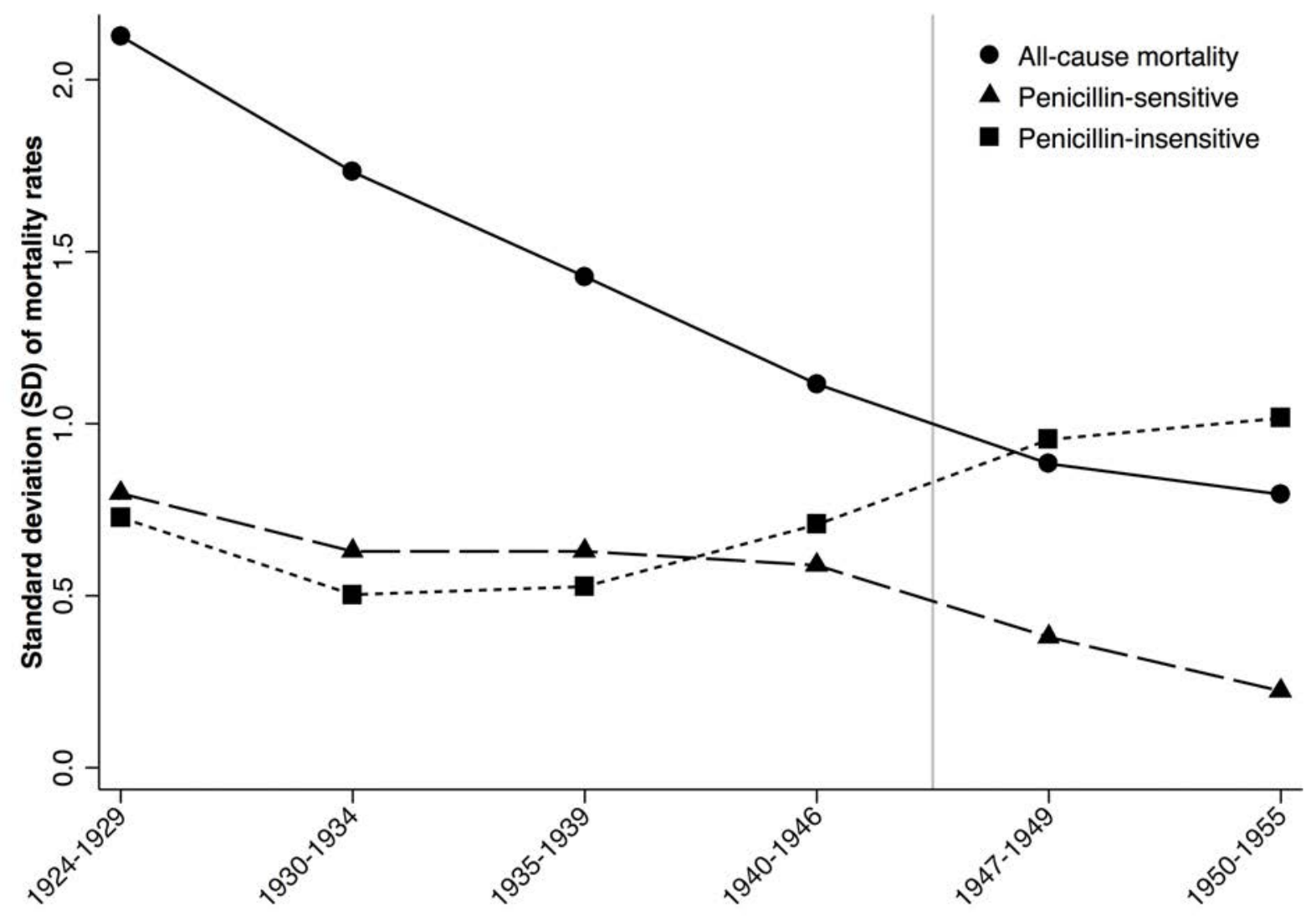

Figure 5: Standard deviation (SD) of all-cause, penicillin-sensitive, and penicillin-insensitive disease mortality in Italy, 1924-1955. The figure shows absolute levels of the SD by age grouped in approximately 5-year bins. For the decade of 1940, we consider two age groups using 1947 as a cut off to illustrate the effect of the introduction of penicillin in that year. 


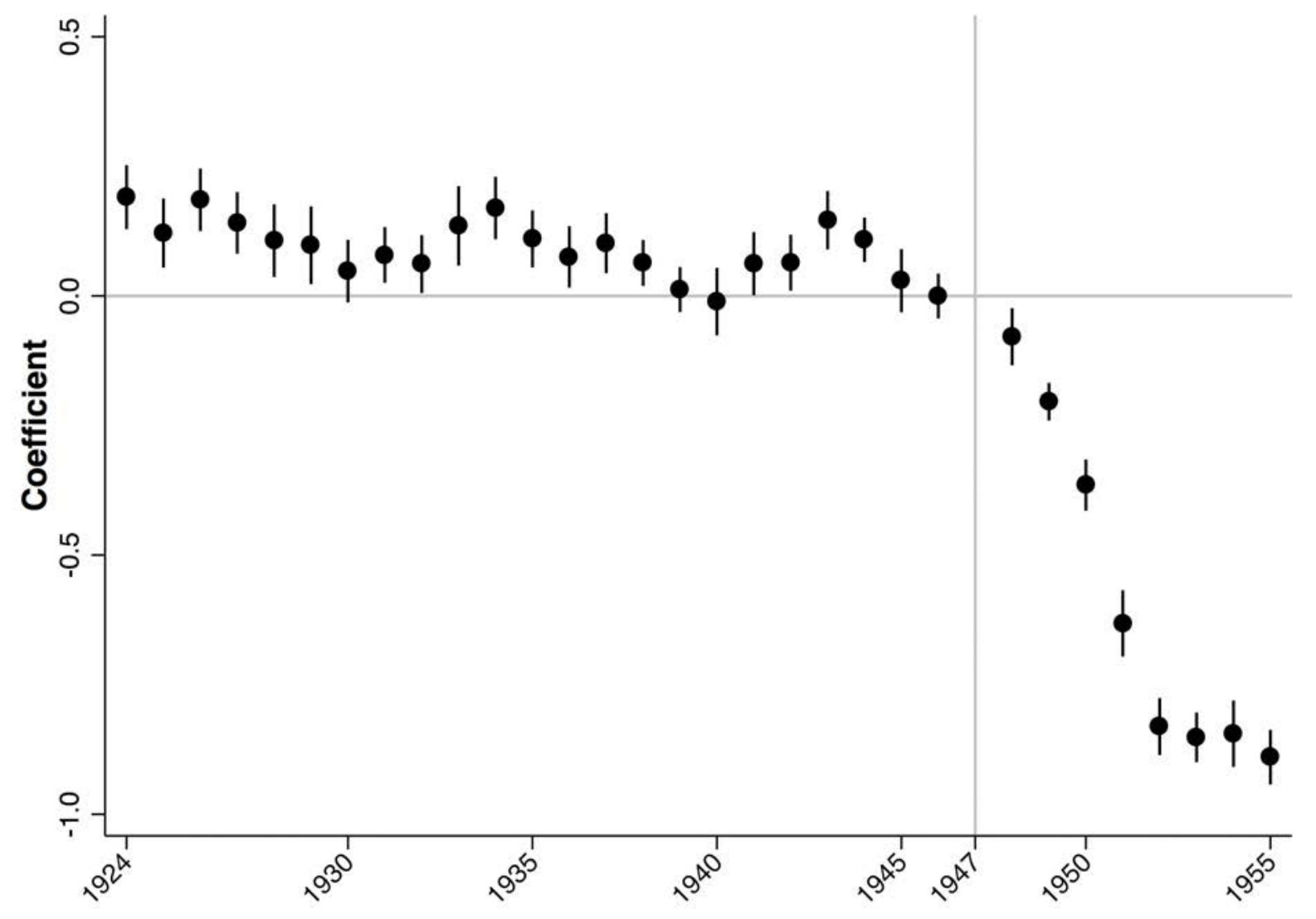

Figure 6: Penicillin-sensitive disease regression coefficients by year (log mortality), 19241955. The figure shows regression coefficients for penicillin-sensitive diseases by year, pre1947 and post-1947. The outcome is log mortality per 1,000. Regression included year and region fixed effects, disease fixed effects, region-disease specific trends, and an interpolated population estimate for age bins 0-25, 26-30, 31-35, 36-40, 41-45, 46-50, 51-55, 56-60, 61-65, 66-70, 71-75, 76+. Standard errors are clustered by region. 


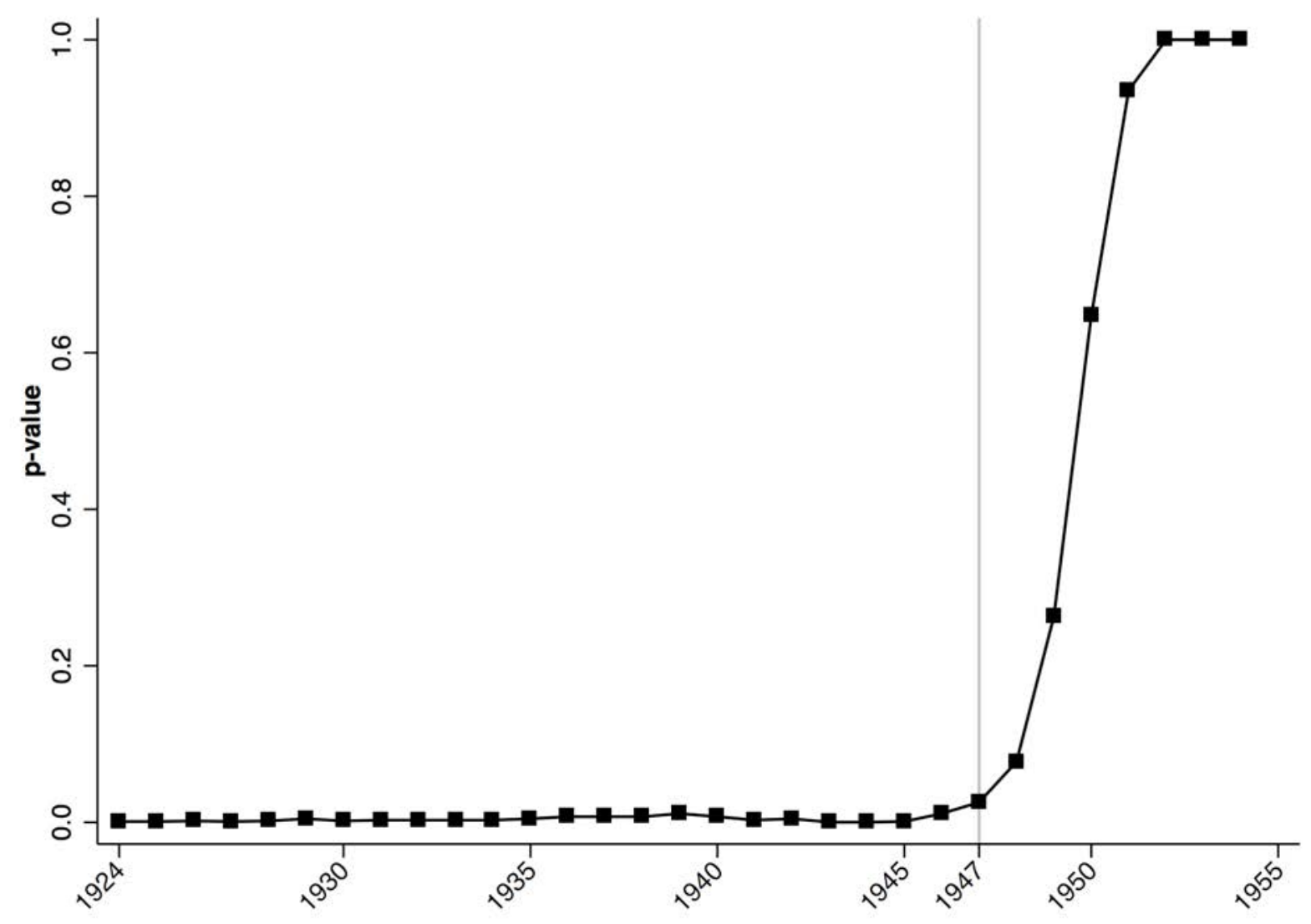

Figure 7: Kolmogorov-Smirnov (KS) test of the equality of age at death mortality distributions in Italy, 1924-1958. The figure illustrates the significance level (p-value) of the KS test for the equality of mortality distributions depicted in Fig. 3, using the distribution of 1955 as the baseline. 
Table 1 Descriptive statistics comparing cause-specific mortality before and after 1947 Descriptive Statistics

\begin{tabular}{|c|c|c|c|}
\hline \multicolumn{4}{|l|}{ 1924-1946 } \\
\hline VARIABLES & $\mathrm{N}$ & Mean & SD \\
\hline $\begin{array}{l}\text { Penicillin-Sensitive Cause-Specific Mortality (per } \\
1,000 \text { ) }\end{array}$ & 3,726 & 0.469 & 0.652 \\
\hline $\begin{array}{l}\text { Penicillin-InsensitiveCause-Specific Mortality (per } \\
\text { 1,000) }\end{array}$ & 11,093 & 0.237 & 0.510 \\
\hline \multicolumn{4}{|l|}{ 1947-1955 } \\
\hline VARIABLES & $\mathrm{N}$ & Mean & SD \\
\hline $\begin{array}{l}\text { Penicillin-Sensitive Cause-Specific Mortality (per } \\
1,000 \text { ) }\end{array}$ & 1,457 & 0.189 & 0.265 \\
\hline $\begin{array}{l}\text { Penicillin-Insensitive Cause-Specific Mortality (per } \\
1,000)\end{array}$ & 4,622 & 0.217 & 0.518 \\
\hline
\end{tabular}

Note: The table reports descriptive statistics on the penicillin-sensitive and -insensitive specific mortality from 1924-1946 and 1947-1955. Cause-specific mortality is the number of deaths per 1,000 people. Source: ISTAT. 
Table 2 Baseline regressions of cause-specific mortality in Italy by regions, 1924-1955

\begin{tabular}{lcccc}
\hline \multirow{2}{*}{ Outcome } & \multicolumn{2}{c}{ Cause-Specific Mortality per } & \multicolumn{2}{c}{$\begin{array}{c}\text { Log Cause-Specific Mortality } \\
\text { per } 1,000\end{array}$} \\
& $(1)$ & $(2)$ & $(3)$ & $(4)$ \\
Sensitive*Post & $-0.272^{* * *}$ & $-0.272^{* * *}$ & $-0.611^{* * *}$ & $-0.610^{* * *}$ \\
& $(0.008)$ & $(0.008)$ & $(0.023)$ & $(0.023)$ \\
Block Bootstrap SE & & & & \\
Block Bootstrap p-value & $(0.008)$ & $(0.008)$ & $(0.022)$ & $(0.023)$ \\
& $\{0.002\}$ & $\{0.002\}$ & $\{0.002\}$ & $\{0.002\}$ \\
Observations & & & & \\
R-squared & 20,898 & 20,898 & 20,892 & 20,892 \\
Year FE & 0.867 & 0.868 & 0.887 & 0.887 \\
Region FE & Yes & Yes & Yes & Yes \\
Disease FE & Yes & Yes & Yes & Yes \\
Region Trends & Yes & Yes & Yes & Yes \\
No. Clusters & No & Yes & No & Yes \\
& 18 & 18 & 18 & 18 \\
\hline
\end{tabular}

Note: The table presents coefficient estimates for the regressions of cause-specific mortality per 1,000 on a dummy variable for disease specific penicillin-sensitivity equal to 1 starting from 1947. In columns (1) and (2) cause-specific mortality per 1,000 is in levels. In columns (3) and (4) cause-specific mortality is in logs. All columns include year, region, disease fixed effects (FE), and interpolated population estimates for age bins 0-25, 26-30, 31-35, 36-40, 41-45, 46-50, 51-55, 56-60,61-65, 66-70, 71-75, 76+. Columns (2) and (4) additionally include region-specific trends. Standard errors (SE) in parentheses are clustered by region. Block bootstrap p-values are indicated in curly brackets 
Table 3 Regression results by median of pre-1947 characteristics in Italy, 19241955

\begin{tabular}{|c|c|c|c|c|c|c|}
\hline \multirow[b]{3}{*}{ Sample } & \multirow[b]{3}{*}{$\begin{array}{l}\text { Above the } \\
\text { Median of } \\
\text { All-Cause } \\
\text { Pre-1947 } \\
\text { Mortality }\end{array}$} & \multirow[b]{3}{*}{$\begin{array}{l}\text { Below the } \\
\text { Median of All- } \\
\text { Cause Pre- } \\
1947 \text { Mortality }\end{array}$} & \multicolumn{4}{|c|}{ Sensitivity to WWII Mortality } \\
\hline & & & $\begin{array}{l}\text { Approach 1: Vary } \\
\text { War-Related }\end{array}$ & $\begin{array}{l}\text { ng Degrees of } \\
\text { Destruction }\end{array}$ & $\begin{array}{r}\text { Approach } \\
\text { (1) and (2) } \\
\text { Betw }\end{array}$ & $\begin{array}{l}\text { Same as Columns } \\
\text { ut Excluding Years } \\
\text { 1943-1945 }\end{array}$ \\
\hline & & & $\begin{array}{l}\text { Regions with } \\
\text { High Destruction }\end{array}$ & $\begin{array}{c}\text { Regions with } \\
\text { Low } \\
\text { Destruction }\end{array}$ & $\begin{array}{l}\text { Above the } \\
\text { Median of } \\
\text { All-Cause } \\
\text { Pre-1947 } \\
\text { Mortality }\end{array}$ & $\begin{array}{c}\text { Below the Median } \\
\text { of All-Cause Pre- } \\
1947 \text { Mortality }\end{array}$ \\
\hline & $(1)$ & (2) & $(3)$ & $(4)$ & (5) & (6) \\
\hline Sensitive*Post & $\begin{array}{c}-0.287 * * * \\
(0.012)\end{array}$ & $\begin{array}{c}-0.257 * * * \\
(0.011)\end{array}$ & $\begin{array}{c}-0.257 * * * \\
(0.011)\end{array}$ & $\begin{array}{c}-0.287 * * * \\
(0.012)\end{array}$ & $\begin{array}{c}-0.303^{* * *} \\
(0.012)\end{array}$ & $\begin{array}{c}-0.271^{* * *} \\
(0.012)\end{array}$ \\
\hline Block Bootstrap SE & $(0.011)$ & $(0.010)$ & $(0.010)$ & $(0.012)$ & $(0.012)$ & $(0.011)$ \\
\hline Block Bootstrap p-value & $\{0.002\}$ & $\{0.004\}$ & $\{0.004\}$ & $\{0.002\}$ & $\{0.004\}$ & $\{0.002\}$ \\
\hline Observations & 10,484 & 10,414 & 10,414 & 10,484 & 9,460 & 9,408 \\
\hline R-squared & 0.875 & 0.901 & 0.899 & 0.873 & 0.873 & 0.899 \\
\hline Year FE & Yes & Yes & Yes & Yes & Yes & Yes \\
\hline Region FE & Yes & Yes & Yes & Yes & Yes & Yes \\
\hline Disease FE & Yes & Yes & Yes & Yes & Yes & Yes \\
\hline Region by Year FE & Yes & Yes & Yes & Yes & Yes & Yes \\
\hline Region Trends & Yes & Yes & Yes & Yes & Yes & Yes \\
\hline
\end{tabular}

Note: The table presents coefficient estimates for the regressions of cause-specific mortality per 1,000 on an indicator variable for disease specific penicillin-sensitivity after year 1947 in comparison to the pre-1947 regional mortality (columns 1-2), and in regions with high and low WWII destruction above the median (columns 3-4). High and low cutoffs are determined respectively by being above and below the median of the given sub sample mortality. Columns 5 and 6 present coefficient estimates for the regressions of annual change of cause-specific mortality per 1,000 on the region-cause specific mortality at a baseline year, based on the first sub-period (1924-1946) and for the second sub-period (1947-1955), respectively. The baseline year is 1924 for the first sub-period, while it is 1947 for the second sub-period. The values in parentheses represent robust standard errors (SE). We test the statistical significance of the difference between the coefficient estimates from columns (1) vs. (2), (3) vs. (4), and (5) vs. (6) by pooling the samples from the corresponding models and looking at the significance level of the estimate of a triple interaction term, that we construct using the indicator variables for disease specific penicillin-sensitivity, post-47 level of mortality, and the corresponding characteristic [e.g., for columns (1) and (2), the interaction term using the pooled sample is Sensitive*Post*(High Penicillin-Sensitive Mortality)]. Cause-specific mortality per 1,000 is in levels. All columns include year, region, disease fixed effects, region-specific trends, and an interpolated population estimate for age bins $0-25,26-30,31-35,36-40,41-45,46-50,51-55,56-60,61-65,66-70,71-75,76+$. Standard errors in parentheses are clustered by region. Block bootstrap p-values are indicated in curly brackets. 
Table 4 Regression results for $\beta$-convergence by high vs. low penicillin-sensitive mortality

\begin{tabular}{lcccc}
\hline \multirow{1}{*}{ Sample } & \multicolumn{2}{c}{ Pre Penicillin Period (1924-1946) } & \multicolumn{2}{c}{ Post Penicillin Period (1947-1955) } \\
& $\begin{array}{c}\text { High Penicillin- } \\
\text { Sensitive } \\
\text { Mortality }\end{array}$ & $\begin{array}{c}\text { Low Penicillin- } \\
\text { Sensitive } \\
\text { Mortality }\end{array}$ & $\begin{array}{c}\text { High Penicillin- } \\
\text { Sensitive } \\
\text { Mortality }\end{array}$ & $\begin{array}{c}\text { Low Penicillin- } \\
\text { Sensitive Mortality }\end{array}$ \\
\hline $\begin{array}{l}\text { Baseline } \\
\text { mortality (1) }\end{array}$ & $-0.021^{* * *}$ & $(2)$ & $(3)$ & $(4)$ \\
or 1947) & & -0.002 & $-0.075^{* * *}$ & $0.009^{* * *}$ \\
& $(0.001)$ & $(0.002)$ & & \\
Observations & 162 & & $(0.002)$ & $(0.002)$ \\
R-squared & 0.913 & 424 & 161 & 508 \\
Region FE & Yes & 0.059 & 0.936 & 0.149 \\
\hline
\end{tabular}

Note:The table presents coefficient estimates for the regressions of annual change of cause-specific mortality per 1,000 on the region-cause specific mortality at a baseline year. Columns 1 and 2 show results for the first sub-period (1924-1946), and columns 3 and 4 for the second sub-period (1947-1955). The baseline year is 1924 for the first sub-period, while it is 1947 for the second sub-period. The values in parentheses represent robust standard errors. 
Table 5 Effect of Penicillin on the Standard Deviation of Mortality Rates and Level of Mortality for Penicillin-Sensitive and -Insensitive Diseases

\begin{tabular}{|c|c|c|c|c|}
\hline Outcome & \multicolumn{2}{|c|}{ Standard Deviation (Sigma-convergence) } & \multicolumn{2}{|c|}{ Mortality Rate } \\
\hline Category & Sensitive & Insensitive & Sensitive & Insensitive \\
\hline & $(1)$ & $(2)$ & (3) & $(4)$ \\
\hline Post (Full Sample -end 1955) & $\begin{array}{c}-0.113^{* * *} \\
(0.014)\end{array}$ & $\begin{array}{l}-0.004 \\
(0.009)\end{array}$ & $\begin{array}{c}-0.600 * * * \\
(0.075)\end{array}$ & $\begin{array}{c}-0.340 * * * \\
(0.095)\end{array}$ \\
\hline Post (Truncated Sample -end 1950) & $\begin{array}{c}-0.090^{* * *} \\
(0.014)\end{array}$ & $\begin{array}{l}-0.009 \\
(0.009)\end{array}$ & $\begin{array}{c}-0.486 * * * \\
(0.075)\end{array}$ & $\begin{array}{c}-0.363 * * * \\
(0.097)\end{array}$ \\
\hline Difference in Post Coefficients (1955-1950) & -0.023 & 0.005 & -0.114 & 0.023 \\
\hline
\end{tabular}

Note: OLS regressions collapsed across deaths within region-years on an indicator for post introduction of Penicillin, region fixed effects, population in various age categories and linear time trends. The outcome in columns (1) and (2) is the standard deviation in mortality for sensitive and insensitive diseases, respectively. The outcome in columns (3) and (4) is the level of mortality from sensitive and insensitive diseases, respectively. Each cell in rows (1) and (2) reports the coefficient on the post indicator. The sample varies by row, extending over the entire analytical time period in row (1) and truncating in 1950 in row (2). Row (3) reports the difference between the full and truncated sample values. If competing risks are driving the results, the effects in row (2) should be considerably less negative in row (1), columns (2) and (4), due to individuals in the lowest part of the health distribution surviving infectious disease due to the introduction of Penicillin but dying at higher rates a few years later from non-communicable mortality. 


\section{Appendix A}

\section{A.1 - The data-set on Causes of Death in Italy (1924-1955)}

In Italy data on mortality are collected routinely by the Italian National Statistical Office (ISTAT) since 1888 and are published in the Health Statistics Yearbooks (Annuari di Statistiche Sanitarie). As disease classifications have changed over time, we can identify 5 time intervals, based on 5 different classifications: 1888-1955, 1956-1957, 1958-1967, 1968-1969 and after 1969. For our study we focus on the 1888-1955 period, although for convenience we use the classification adopted in 1956-1957 as our reference classification (it presents the less disaggregated set of information: 17 main causes of death and 99 more specific pathologies) and, therefore, we have re-organized the 1888-1955 classifications to reflect the 1956-1957 classification.

Originally, data for the period 1888-1955 were available only on paper in a single document printed by ISTAT (ISTAT, 1958) and presented in form of time series by region and cause of death. For our purposes all tables have been scanned and saved in form of excel files. These row data have been further processed and double-checked in order to avoid errors from the scanning process. During the 1888-1955 period the classification follows the International Analytical Classification (IAC) code, which was approved in 1948 (ICD, 1948) and adopted in Italy from 1951. The reconstruction of the time series before year 1951 has been carried out by ISTAT. The classification adopted in 1956 and 1957 has changed from the IAC to the ISTAT Intermediate Classification (IIC) coding system. Table A.1 provides a detailed list of all diseases with the relative IIC code, while Table A.2 provides a link between the IIC and the IAC coding system.

The first column provides a brief description of the 17 main causes of death; the second column reports the ISTAT classification used to identify causes (ranging from I to XVII) and pathologies (ranging from 1 to 99); the third column describes the identification code that we implemented starting from the ISTAT classification. It consists of 7 digits: the first 3 digits denote 1 out of the 17 causes of death (101 to 117); the following 2 digits denote 1 out of the 99 pathologies (from 01 to 99). The final 2 digits range from 00 to 10: they equal zero for any of the 99 pathologies resulting from the 1956-1957 classification, and take on different values (from 01 to 10) for further disaggregation of pathologies possibly occurred either between years 1888-1955. In terms of regional disaggregation it is worth mentioning that until 1923 data refers to the Italian partition of territories prior to the WWI; from 1924 to 1942, data are referred to the borders established after WWI; from 1943 onward, to the borders after the WWII. Data prior to 1943 are referred, for each region, to the partition of territories adopted at that time. Thus, the comparability across territories is imperfect for those regions that have experienced border changes from 1927 (i.e., Veneto, Friuli-Venezia Giulia, Umbria, Lazio, Abruzzi, Molise and Campania). To account for these geographical border changes and in order to have an harmonized regional disaggregation, we have grouped together Abruzzi and Molise and Piedmont and Valle dAosta, that leads to have the dataset disaggregated in the following 18 regions: Piedmont and Valle dAosta, Lombardy, Trentino Alto Adige, Veneto, Friuli Venezia Giulia, Liguria, Emilia Romagna, Tuscany, Umbria, Marche, Lazio, Abruzzi and Molise, Campania, Apulia, Basilicata, Calabria, Sicily and Sardinia. 


\section{A.2 - Construction of mortality rates}

Mortality rates are obtained dividing number of deaths by resident population. Unfortunately, data on resident population by region is available only starting from 1922 and is obtained through a reconstruction made by Golini, Ciucci, Caselli and ISTAT (1983). As it is only from 1924 that Italy was organized in 18 administrative regions (with only minor changes with small borderline municipalities changing regions after that date) we decided to start our analysis starts in 1924. For all these reasons we limit our analysis from 1924 to 1955. 
Table A.1. Structure of the 1956 -1957 classification (reference classification)

\begin{tabular}{lcccc}
\hline \multicolumn{1}{c}{ Description } & \multicolumn{1}{c}{ 1956-1957 ISTAT Classification } & \multicolumn{2}{c}{ Code ("number") } \\
& Causes of death & Pathologies (IIC) & Causes of death & Pathologies \\
\hline Infective/parasitic diseases & I & $1-10$ & 1010000 & $1010100-1011000$ \\
Tumors & II & $11-26$ & 1020000 & $1021100-1022600$ \\
Allergic/endocrine glands diseases & III & $27-31$ & 1030000 & $1032700-1033100$ \\
Blood/hematopoietic diseases & IV & $32-33$ & 1040000 & $1043200-1043300$ \\
Psychic/personality disorders & V & $34-36$ & 1050000 & $1053400-1053600$ \\
Nervous system diseases & VI & $37-45$ & 1060000 & $1063700-1064500$ \\
Circulatory system diseases & VII & $46-56$ & 1070000 & $1074600-1075600$ \\
Respiratory system diseases & VIII & $57-60$ & 1080000 & $1085700-1086000$ \\
Digestive system diseases & IX & $61-70$ & 1090000 & $1096100-1097000$ \\
Genitourinary system diseases & X & $71-76$ & 1100000 & $1107100-1107600$ \\
Complications of pregnancy & XI & $77-80$ & 1110000 & $1117700-1118000$ \\
Skin/tissue diseases & XII & 81 & 1120000 & 1120000 \\
Bones locomotive organs diseases & XIII & $82-84$ & 1130000 & $1138200-1138400$ \\
Congenital malformations & XIV & $85-86$ & 1140000 & $1148500-1148600$ \\
Early Childhood particular diseases & XV & $87-91$ & 1150000 & $1158700-1159100$ \\
Senility and pathologic states & XVI & $92-93$ & 1160000 & $1169200-1169300$ \\
Accidents/traumatisms/poisonings & XVII & $94-99$ & 1170000 & $1179400-1179900$ \\
Total deaths & XVIII & & 1180000 & 1180000 \\
& & & &
\end{tabular}


Table A.2 - Causes of death by ISTAT Identificat/on Code (IIC) and International Classification Code (ICC)

\begin{tabular}{|c|c|c|c|}
\hline \multicolumn{2}{|c|}{ IIC Code } & \multirow[t]{2}{*}{ Description } & \multirow[t]{2}{*}{ International Classification Code } \\
\hline Code (1) & Code (2) & & \\
\hline \multirow{9}{*}{1010000} & 1010101 & All forms of tuberculosis & 001-019 \\
\hline & 1010300 & Syphilis and consequences & $020-029$ \\
\hline & 1010400 & Typhoid and paratyphoid fevers & 040,041 \\
\hline & 1010500 & Diphtheria & 055 \\
\hline & 1010600 & Pertussis & 056 \\
\hline & 1010700 & Tetanus & 061 \\
\hline & 1010800 & Acute anterior poliomyelitis & 080,081 \\
\hline & 1010900 & Measles & 085 \\
\hline & 1011000 & Other infectious and parasitic diseases & $\begin{array}{l}044,045-048,050,052,053,063 \\
057,062,082,083,110-117,125\end{array}$ \\
\hline \multirow{5}{*}{1020000} & 1021101 & All malignant tumors & $140-200,202,203$ \\
\hline & 1022301 & Hodgkin disease & 201 \\
\hline & 1022400 & Leukemia/a-leukemia & 204 \\
\hline & 1022600 & All benign tumors & $210-229$ \\
\hline & 1022608 & Tumors of not specified origins & $230-239$ \\
\hline \multirow{4}{*}{1030000} & 1032900 & Diabetes & 260 \\
\hline & 1032804 & Diseases of thyroid and parathyroid glands & $250-254,271$ \\
\hline & 1032700 & Allergic diseases & 240,241 \\
\hline & 1033001 & Diseases of other endocrine glands and other metabolism diseases & $281,283,284,288$ \\
\hline \multirow{3}{*}{1040000} & 1043203 & Other anemias & $290.2,291-293$ \\
\hline & 1043300 & Other blood diseases and hematopoietic organs & 295,296 \\
\hline & 1043201 & Pernicious anemias and other hyper-chronic diseases & 290.0 .1 \\
\hline 1050000 & & Psychic/ personality disorders (alcoholism only) & 322 \\
\hline \multirow{5}{*}{1060000} & 1063900 & Vascular lesions of central nervous system & $330-334$ \\
\hline & 1064001 & Meningitis & 340 \\
\hline & 1064100 & Epilepsy & 353 \\
\hline & 1064201 & Cerebral paralysis & 350 \\
\hline & 1064400 & Eyes diseases & $370-398$ \\
\hline 1070000 & & Circulatory system diseases & $400-468$ \\
\hline \multirow{4}{*}{1080000} & 1085703 & Influenza & $480-483$ \\
\hline & 1085700 & Pneumonia & $490-493,763$ \\
\hline & 1085900 & Bronchitis & 500-502 \\
\hline & 1086008 & Pleurisy & 518,519 \\
\hline \multirow{8}{*}{1090000} & 1096104 & Stomach and duodenal ulcers and other diseases of stomach/duodenum & $540-545$ \\
\hline & 1096200 & Appendicitis & $550-553$ \\
\hline & 1096302 & Abdominal hernia with obstruction & $560,561,570$ \\
\hline & 1096600 & Gastroenteritis, colitis and ulcerative colitis & $571,572,764,772$ \\
\hline & 1097004 & Peritonitis & 576,577 \\
\hline & 1096700 & Liver cirrhosis & 581 \\
\hline & 1096900 & Other diseases of liver, pancreas & $580,582,583$ \\
\hline & 1096801 & Bladder diseases and biliary tract diseases & $584-586$ \\
\hline 1100000 & & Genitourinary system diseases & $590-637$ \\
\hline 1110000 & & Complications of pregnancy & $640-689$ \\
\hline 1120000 & & Skin/tissue diseases & $690-716$ \\
\hline 1130000 & & Bones locomotive organs diseases & $720-749$ \\
\hline 1140000 & & Congenital malformations & $750-759$ \\
\hline 1150000 & & Early Childhood particular diseases & 760-762,765-771,773-776 \\
\hline 1160000 & & Senility and pathologic states & 304,794 \\
\hline \multirow{3}{*}{1170000} & 1179701 & Accidental deaths & $E(800-965,999)$ \\
\hline & 1179800 & Suicides & $E(970-979)$ \\
\hline & 1179900 & Homicides & $E(980-985)$ \\
\hline
\end{tabular}




\section{Appendix B}

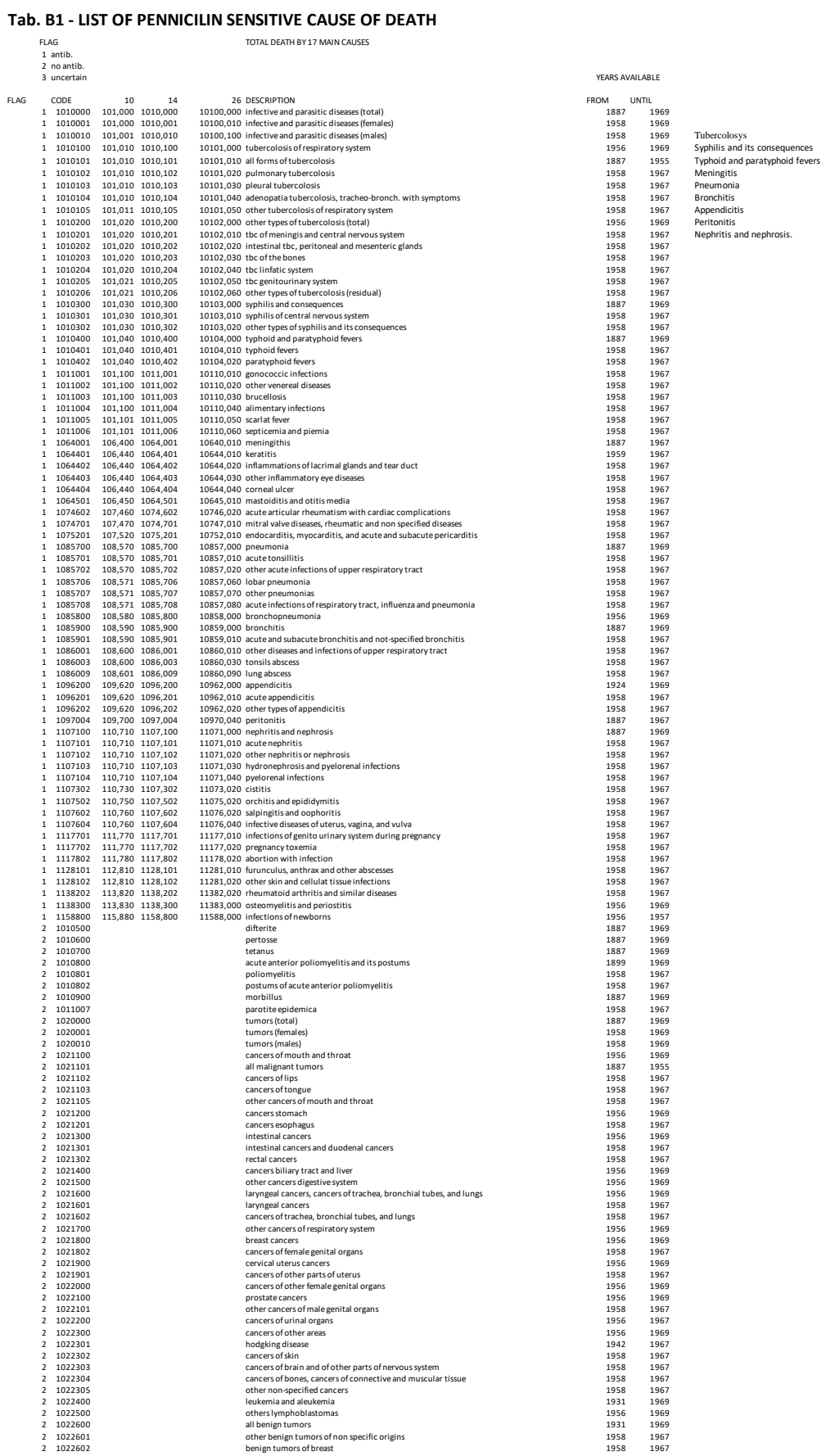


Tab. B1 - LIST OF PENNICILIN SENSITIVE CAUSE OF DEATH - Cntd

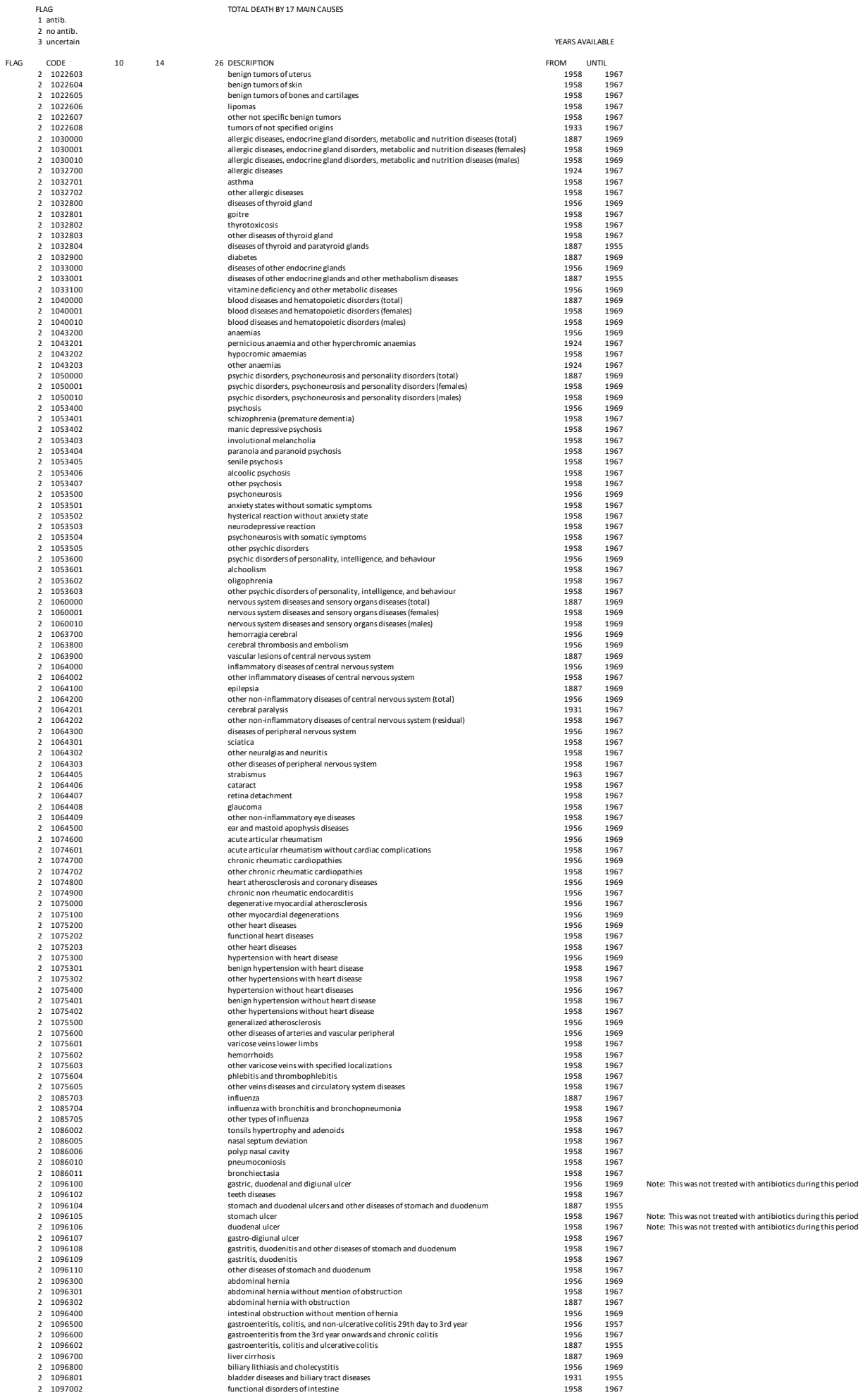



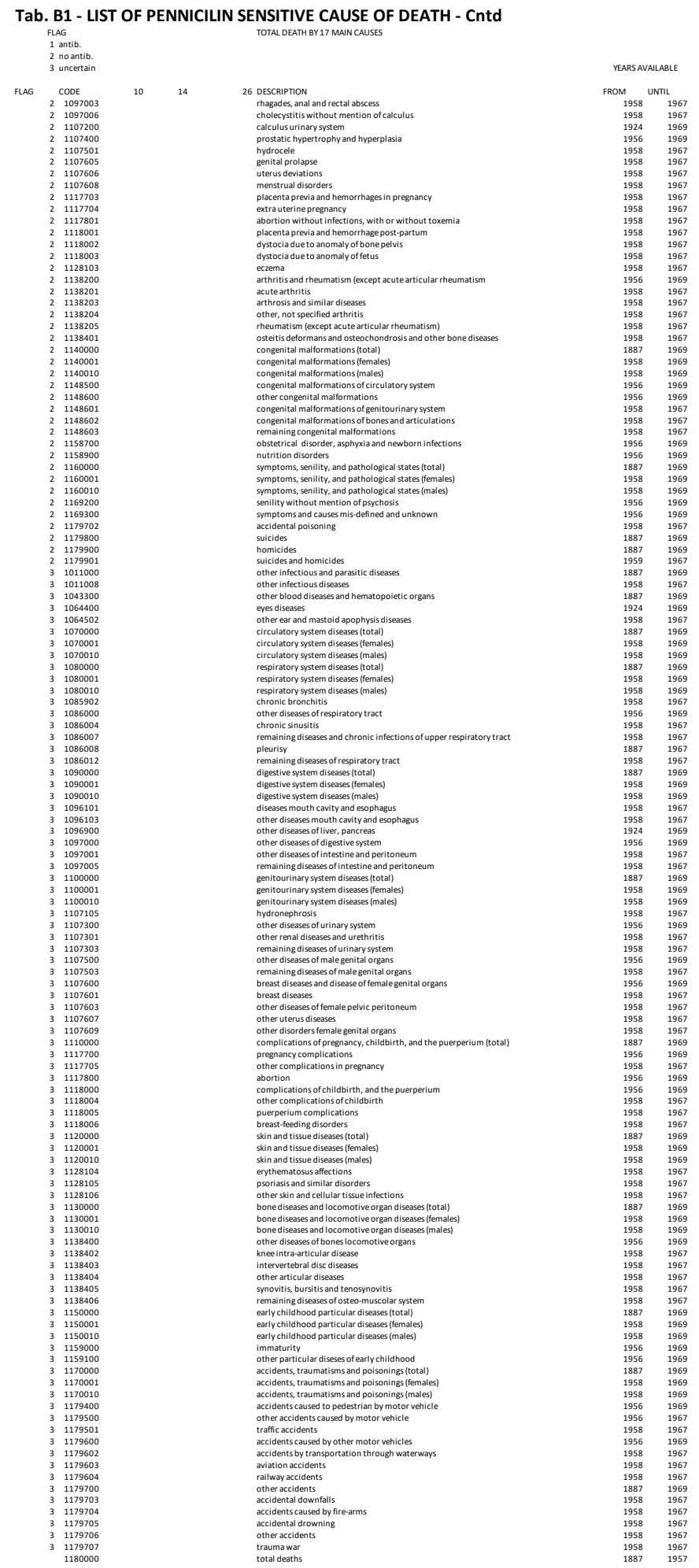